\title{
Jardim de chuva: sistema de biorretenção para o manejo das águas pluviais urbanas
}

\author{
Rain garden: bioretention system for urban stormwater \\ management
}

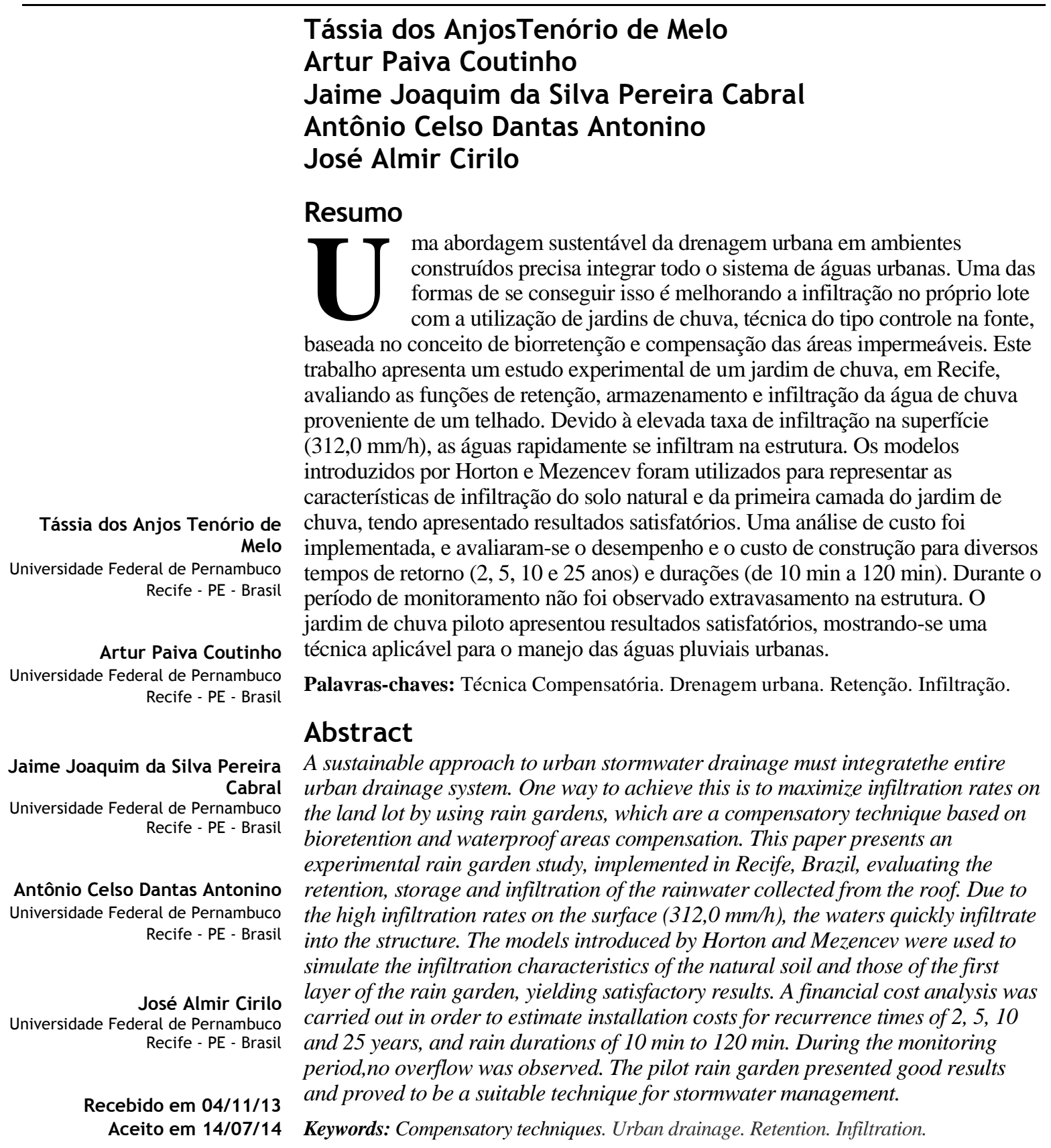

MELO, T. dos A. T. DE; COUTINHO, A. P.; CABRAL, J. J. da S. P.; ANTONINO, A. C. D.; CIRILO, J. A. Jardim de chuva: 147 sistema de biorretenção para o manejo das águas pluviais urbanas. Ambiente Construído, Porto Alegre, v. 14, n. 4, p. 147-165, out./dez. 2014.

ISSN 1678-8621 Associação Nacional de Tecnologia do Ambiente Construído. 


\section{Introdução}

De acordo com o IBGE (2011), a população brasileira aumentou $49 \%$ nos últimos 40 anos, principalmente em áreas urbanas. Atualmente, $84 \%$ da população vive em áreas urbanas, o que resulta no "inchaço" da maioria das cidades brasileiras.

Os processos de urbanização que ocorrem sobre as bacias urbanas geram forte pressão espacial, tornando-as cada vez mais vulneráveis às modificações de uso e ocupação do solo, principalmente pelo avanço das áreas impermeáveis.

O processo de impermeabilização proporciona significativas mudanças na dinâmica do sistema de drenagem, como o aumento do volume e da velocidade do escoamento superficial, de forma a acarretar a sobrecarga no sistema de drenagem existente. Esses fatores aumentam a frequência de alagamentos e cheias (CUO et al., 2009).

É essencial uma mudança nos paradigmas existentes acerca da importância ambiental no espaço urbano, associando aspectos do processo de urbanização e a drenagem urbana. Dessa maneira, faz-se necessário aprimorar as práticas de manejo das águas pluviais urbanas.

Em planos diretores de drenagem urbana (PDDU), abordagens inovadoras de manejo das águas pluviais urbanas têm sido empregadas. Esse conceito recebe denominações como LID (Low Impact Development), SUDS (Sustainable Urban Drainage System) e WSUD (Water Sensitive Urban Design) (BAPTISTA; NASCIMENTO; BARRAUD, 2011).

Inseridas nesses conceitos, algumas técnicas são adotadas para compensar as consequências negativas do processo de urbanização. Denominadas de técnicas compensatórias em drenagem urbana, elas visam preservar os mecanismos naturais de escoamento, diminuindo as vazões a jusante, maximizando o controle de escoamento na fonte e mitigando os impactos ambientais. Essas alternativas se baseiam em processos de armazenamento, detenção, retenção, interceptação, evapotranspiração e infiltração das águas pluviais (DAVIS, 2008; NASCIMENTO; BAPTISTA, 2009; ROY-POIRIER; CHAMPAGNE; FILION, 2010; BAPTISTA; NASCIMENTO; BARRAUD, 2011; SANTOS et al., 2013).

Os sistemas de biorretenção são instalados em áreas escavadas, preenchidos com material granular de alta permeabilidade e material orgânico, beneficiando, assim, as principais funções do sistema: retenção, filtração e infiltração.

Os jardins de chuva são os sistemas de biorretenção mais conhecidos. Valorizam a desconexão de áreas impermeáveis, dirigindo as águas para si, de forma a contribuir no manejo das águas pluviais em meio urbano e a proporcionar benefícios ambientais, ecológicos, paisagísticos e econômicos (DIETZ; CLAUSEN, 2006; ARAVENA; DUSSAILLANT, 2009).

Li e Zhao (2008) descrevem o jardim de chuva como uma estrutura hidrológica funcional na paisagem, de baixo investimento e manutenção simplificada, no qual, através do sistema soloplanta-atmosfera e processos de infiltração, retenção e adsorção, purifica e absorve as águas pluviais de pequenas áreas, reduzindo o volume escoado e protegendo as águas subterrâneas.

Sua função de retenção é projetada para captar, reter, retardar e minimizar ou evitar os impactos advindos do escoamento superficial. Nessa etapa as águas são conservadas sobre sua superfície e depois se infiltram ou evaporam.

Concomitantemente ao processo de infiltração, ocorre a filtração nos jardins de chuva. A função de filtração é bastante abordada, devido a sua capacidade na remoção de poluentes carreados pelo escoamento superficial (DAVIS et al., 2009; TROWSDALE; SIMCOCK, 2011). Pesquisas constataram que os principais poluentes removidos são os sólidos suspensos totais, nitratos, fósforo total, zinco e metais pesados (Quadro 1).

Em um jardim de chuva, duas questões são importantes em relação a seu desempenho hidráulico/hidrológico: o controle da quantidade de água escoada, através de suas depressões e cotas mais baixas, o que facilita a captação e a retenção da água; e a melhoria da qualidade das águas retidas, através da remoção de poluentes e da associação de nutrientes advindos do escoamento superficial (DUNNETT; CLAYDEN, 2007).

Em relação ao projeto, alguns autores consideram os jardins de chuva sistemas ideais para serem implantados em áreas residenciais, principalmente em quintais, onde os sistemas são dimensionados justamente para receber volumes de calçadas e telhados. Frequentemente, o tamanho dos jardins de chuva é destinado a pequenas áreas, sendo adotado um critério mínimo de dimensionamento de $5 \%$ da área da superfície impermeável (CHRISTENSEN; SCHMIDT, 2008; LI; ZHAO, 2008; LI; CHE; GE, 2010; WINSTON et al., 2010).

148 Melo, T. dos A. T. de; Coutinho, A. P.; Cabral, J. J. da S. P.; Antonino, A. C. D.; Cirilo, J. A. 
Azzout et al. (1994), Davis et al. (2009) e He e Davis (2011) consideram que os critérios de projeto devem ser específicos e priorizar o estudo do solo, principalmente sua permeabilidade e considerações sobre as variações de nível do lençol subterrâneo, podendo ser este último uma limitação de projeto quando muito próximo da superfície do solo.

Já outros autores baseiam seus projetos em processos do ciclo hidrológico. Prince George's County (2007), através do Método da CurvaNúmero $(\mathrm{CN})$, utiliza dados de chuva diária a fim de estimar o escoamento superficial para um dia. Já Winston et al.(2010) propõem uma metodologia de projeto baseada no tempo de infiltração das águas em solo natural.

Flynn e Traver (2013) realizaram um estudo sobre os possíveis impactos negativos gerados por jardins de chuva. Constataram que é na fase de projeto e construção do experimento que as prováveis causas dos impactos são geradas e que esses podem comprometer o custo e o ciclo de vida do sistema.

No que tange à estrutura do jardim de chuva, Dunnett e Clayden (2007) propõem uma estrutura composta de seis camadas, a partir do limite de profundidade, como representado na Figura 1. O Quadro 2 apresenta algumas estruturas de jardim de chuva propostas na literatura.

Os processos que ocorrem na natureza, como fitorremediação, decomposição, desnitrificação, evapotranspiração e adsorção, são os mesmos que existem no jardim de chuva, em menor escala. $\mathrm{O}$ desenho, a estrutura do jardim de chuva e as condições ambientais locais interferem nesses processos.

A cobertura vegetal utilizada tem relevância no desempenho do sistema, por participar da função de evapotranspiração, do tratamento de determinados poluentes e, principalmente, por atuar hidraulicamente no prolongamento da capacidade de infiltração do sistema (LE COUSTUMER et al., 2012).

\section{Quadro 1 - Percentuais das remoções de materiais pela função de filtração dos jardins de chuva}

\begin{tabular}{|c|c|c|}
\hline Parâmetros & \% removido & \multirow{7}{*}{$\begin{array}{l}\text { Descriçao ao experimento } \\
{ }^{1} \text { Solo arenoso coberto com aproximadamente } 5 \mathrm{~cm} \text { de } \\
\text { folhagens, cobertura vegetal composta de gramíneas, arbustos } \\
\text { e pequenas árvores. } \\
{ }^{2} \text { Camada de reservatório }(1,21 \mathrm{~m}) \text { com dreno lateral para } \\
\text { extravasamento e borda livre }(50 \% \text { da camada de reservatório). } \\
{ }^{3} \text { Camada de areia lavada }(75 \mathrm{~cm}) \text {, camada de solo poroso ( } 15 \\
\mathrm{~cm}) \text {, camada de folhas secas }(5 \mathrm{~cm}) \text {. Solo natural do tipo } \\
\text { siltoso. } \\
{ }^{4} \mathrm{Mistura} \text { de areia extraída de uma pedreira e cobertura vegetal } \\
\left.\text { (um arbusto a cada } 2,3 \mathrm{~m}^{2}\right) \text {. Área equivalente a } 14,9 \% \text { da área } \\
\text { da bacia. A condutividade hidráulica do solo natural é inferior } \\
\text { a } 0,42 \text { mm/s. } \\
{ }^{5} \text { Tubulação para drenagem envolvida por pedras e uma manta } \\
\text { para proteção; uma camada de material orgânico; borda livre } \\
\text { revestida de folhas secas ( } 15 \text { cm), cobertura vegetal com } \\
\text { arbustos e árvores. Área equivalente a } 5 \% \text { da área da bacia. A } \\
\text { condutividade hidráulica do solo é de } 0,11 \text { mm/s. } \\
{ }^{6} \text { Camada filtrante composta de } 60 \% \text { de areia, } 20 \% \text { de lascas de } \\
\text { madeira, } 10 \% \text { de composto orgânico e } 10 \% \text { de solo natural } \\
\text { (76,2 cm de profundidade), cobertura vegetal composta de } \\
\text { vegetação tolerante a inundação e a seca. }\end{array}$} \\
\hline $\begin{array}{l}\text { TSS - sólidos } \\
\text { totais suspensos }\end{array}$ & $\begin{array}{l}{ }^{2} 91,7 \\
{ }^{3} 91\end{array}$ & \\
\hline $\begin{array}{l}\mathrm{NTP} \text { - fósforo } \\
\text { total }\end{array}$ & $\begin{array}{c}{ }^{2} 33,9 \\
{ }^{3} 63 \\
{ }^{1} 65 \\
{ }^{4} 65\end{array}$ & \\
\hline $\begin{array}{c}\mathrm{TN} \text { - nitrogênio } \\
\text { total }\end{array}$ & $\begin{array}{c}538 \\
440 \\
{ }^{4} 47,9 \\
149\end{array}$ & \\
\hline $\mathrm{Cu}$ - cobre & $\begin{array}{c}{ }^{2} 46,5 \\
197\end{array}$ & \\
\hline $\mathrm{Pb}-$ chumbo & $\begin{array}{c}195 \\
255,2\end{array}$ & \\
\hline $\mathrm{Zn}-$ zinco & $\begin{array}{c}{ }^{2} 16,9 \\
668 \\
{ }^{6} 65\end{array}$ & \\
\hline
\end{tabular}

Fonte: adaptado de Prince George's County (2007).

Nota: ${ }^{1}$ Davis et al. (2006); ${ }^{2}$ Ermilio (2005); ${ }^{3}$ Hsieh e Davis (2003); ${ }^{4}$ Hunt et al. (2006); ${ }^{5}$ Sharkey (2006);

${ }^{7}$ University of New Hampshire Stormwater Center (2009). 
Figura 1 - Estrutura básica proposta para um jardim de chuva

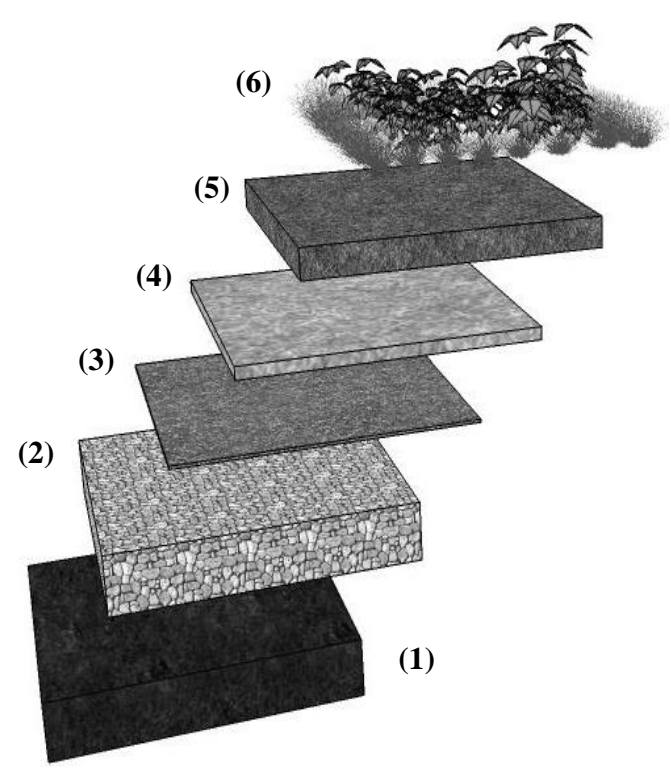

(6) Camada superficial onde são dispostas as vegetações do jardim de chuva, recomendando-se a utilização de gramíneas, plantas rasteiras, arbustivas e de espécies nativas, por se adaptarem melhor ao clima da região. (5) Local que contém todos os nutrientes que darão suporte à cobertura vegetal utilizada.

(4) Camada formada, em sua maioria, por areia, para estimular a infiltração e a redistribuição da água no solo. (3) Camada constituída por uma manta geotêxtil, destinada à retenção de finos carreados no processo de infiltração.

(2) Camada formada por brita ou cascalho, onde a água é temporariamente abrigada antes de ser destinada ao solo natural.

(1) Local onde a água infiltrada pode ser utilizada para recarga subterrânea, armazenamento ou ambos - sistema combinado.

Fonte: adaptado de Dunnett e Clayden (2007).

Quadro 2 - Apresentação de algumas estruturas de jardim de chuva propostas na literatura

\begin{tabular}{|c|c|}
\hline Referência & Estrutura das camadas proposta \\
\hline $\begin{array}{l}\text { Dussaillant, Wu e } \\
\text { Potter, } 2004\end{array}$ & $\begin{array}{l}\text { 1. Subsolo urbano sem espessura definida; } 2 \text {. Geotêxtil (manta } \\
\text { filtrante); } 3 \text {. Areia }-70 \mathrm{~cm} \text {; } 4 \text {. Adubação }-50 \mathrm{~cm} \text { de mistura }(60 \% \\
\text { de areia e } 40 \% \text { de matéria orgânica); } 5 \text {. Cobertura vegetal. }\end{array}$ \\
\hline $\begin{array}{c}\text { Aravena e } \\
\text { Dussaillant, } 2009\end{array}$ & $\begin{array}{l}\text { 1. Areia }-150 \mathrm{~cm} ; 2 \text {. Adubação }-50 \mathrm{~cm} \text { de mistura }-50 \% \text { de areia e } \\
50 \% \text { de composto orgânico; } 3 \text {. Cobertura vegetal. }\end{array}$ \\
\hline $\begin{array}{l}\text { Muthanna, Viklander } \\
\text { e Thorolfsson, } 2008\end{array}$ & $\begin{array}{l}\text { 1. Cascalho }-10 \mathrm{~cm} ; 2 \text {. Malha fina de plástico (filtração); } 3 \text {. Areia } \\
\text { grossa }-50 \mathrm{~cm} ; 4 \text {. Adubação }-5 \text { a } 10 \mathrm{~cm} ; 5 \text {. Bordo livre para } \\
\text { retenção }-15 \mathrm{~cm} ; 6 \text {. Cobertura vegetal. }\end{array}$ \\
\hline $\begin{array}{l}\text { Trowsdale e } \\
\text { Simcock, } 2011\end{array}$ & $\begin{array}{l}\text { 1. Areia }-15 \mathrm{~cm} ; 2 \text {. Calcário }-60 \text { a } 70 \mathrm{~cm} ; 3 \text {. Solo misto }-30 \text { a } 40 \\
\mathrm{~cm} \text { - pedregulhos e solo fértil; } 4 \text {. Mistura de folhas }-5 \mathrm{~cm} ; 5 . \\
\text { Cobertura vegetal. }\end{array}$ \\
\hline
\end{tabular}

A partir da abordagem conceitual sobre o tema, este trabalho apresenta um estudo sobre um jardim de chuva instalado em Recife e analisa a sensibilidade do dimensionamento, modelagem aplicada à infiltração, custo e comportamento do sistema em relação às funções de retenção, infiltração e armazenamento.

\section{Material e métodos}

\section{Descrição da área de estudo}

A planície do Recife está localizada um pouco acima do nível do mar ( $2 \mathrm{~m}$ a $10 \mathrm{~m}$ ), e em algumas áreas seus níveis são equivalentes aos níveis das marés de sizija. Além disso, a cidade é rodeada por morros e elevações topográficas, o que proporciona o acúmulo de água em seu interior, dificultando a drenagem natural das águas em épocas chuvosas.

Com um clima tropical quente e úmido do tipo As, de acordo com a classificação climática de Köppen, a temperatura média histórica anual do município é de $23,9^{\circ} \mathrm{C}$, e a média histórica anual da precipitação é de $2.254 \mathrm{~mm}$ (LAMEPE/ITEP, 2010).

Os problemas de alagamento na planície de Recife intensificam-se devido ao aumento de áreas impermeáveis; precariedade do sistema de micro e macrodrenagem, pela falta de manutenção, fiscalização e educação da população.

$\mathrm{O}$ jardim de chuva piloto, utilizado durante o estudo, foi instalado na Universidade Federal de Pernambuco (CTG/UFPE), e projetado para receber águas advindas do escoamento superficial

150 Melo, T. dos A. T. de; Coutinho, A. P.; Cabral, J. J. da S. P.; Antonino, A. C. D.; Cirilo, J. A. 
de uma área de $74,80 \mathrm{~m}^{2}$, equivalente a uma fração do telhado do Laboratório de Hidráulica.

A caracterização do solo natural foi determinada mediante amostras de solo coletadas até a profundidade de $1 \mathrm{~m}$, utilizando-se a NBR 7181 (1984) e a classificação textural da Embrapa (SANTOS, 2006) (Tabela 1). A taxa de infiltração da superfície do solo natural é de $28,49 \mathrm{~mm} / \mathrm{h}$.

A percentagem de matéria orgânica da primeira camada do jardim de chuva piloto foi determinada pelo Método Walkley-Black modificado (SILVA, 1999).

\section{Descrição do experimento}

\section{Definição das dimensões do experimento}

A escolha das dimensões do jardim de chuva piloto foi dividida em duas partes: área e estrutura. Em relação à área foram determinadas as dimensões planas do jardim; já na estrutura foi estudado o dimensionamento das camadas internas do jardim de chuva piloto.

A área total do experimento foi baseada na porcentagem mínima da área impermeável adotada na literatura. A área total do telhado é de $74,80 \mathrm{~m}^{2}$, e, considerando 5\% dessa área, o jardim de chuva piloto deveria ter uma área de $3,74 \mathrm{~m}^{2}$. Para efeitos de cálculo e regularidade no desenho do experimento, a área adotada foi de $4,00 \mathrm{~m}^{2}$, sendo 2,00 m cada lado.

Para o dimensionamento da estrutura do jardim piloto, um dos pontos mais importantes é a camada de armazenamento, representada pela altura de brita a ser adotada. Essa medida foi determinada seguindo as etapas de cálculo da Figura 2.

Para determinar a intensidade de precipitação (I), utilizou-se a equação de intensidade-duraçãofrequência (i-d-f) proposta por Ramos e Azevedo (2010) (Equação 1).

$\mathrm{i}=\frac{1.423,97 \cdot T_{r}^{0,1124}}{(\mathrm{t}+21)^{0,7721}}$

Sendo:

$\mathrm{i}=$ intensidade da precipitação $[\mathrm{L} / \mathrm{T}], \mathrm{mm} / \mathrm{h}$;

$\operatorname{Tr}=$ tempo de retorno, $[\mathrm{T}]$, em anos; e

$\mathrm{t}=$ duração do evento, $[\mathrm{T}]$, em minutos

Foram calculadas intensidades de precipitação para diferentes tempos de retorno (2, 5 e 10 anos), visando a uma análise comparativa das espessuras das camadas de armazenamento necessárias para durações da chuva de projeto de até $2 \mathrm{~h}$. As durações das chuvas utilizadas na equação idf foram baseadas nos dados dos ensaios de infiltração (Figura 3).

Tabela 1 - Classificação textural do solo natural onde foi implantado o jardim de chuva piloto da UFPE, em 2011

\begin{tabular}{c|c|c|c|c}
\hline Camadas (cm) & Argila (\%) & Silte (\%) & Areia (\%) & Classificação textural \\
\hline $00-20$ & 28,14 & 15,07 & 56,79 & Franco argiloarenoso \\
$20-50$ & 16,41 & 28,99 & 54,59 & Franco arenoso \\
$50-100$ & 17,59 & 36,17 & 46,24 & Franco \\
\hline
\end{tabular}

Figura 2 - Etapas de cálculo adotadas no dimensionamento da estrutura do jardim de chuva piloto da UFPE

I. INTENSIDADE DE PRECIPITAÇÃO

II. ALTURA DE PRECIPITAÇÃO

III. VOLUME DE ENTRADA

IV. VOLUME DE SAÍDA

V. ALTURA DE BRITA

DIMENSÕES ADOTADAS 
Figura 3 - Intensidade de precipitação para os tempos de retorno de 2, 5 e 10 anos

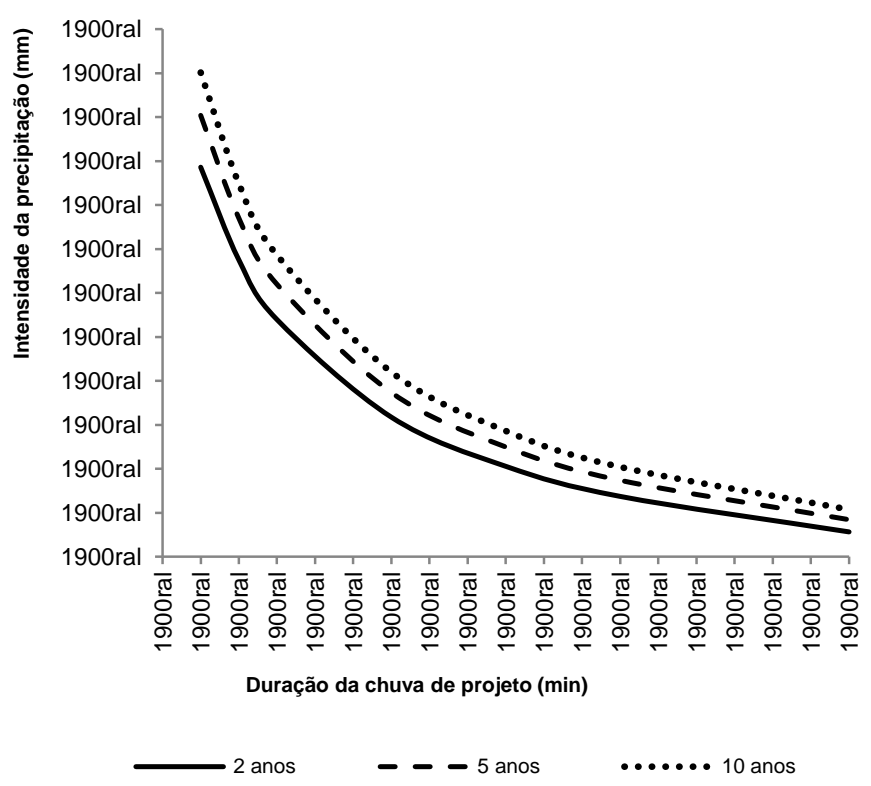

As alturas de precipitação (II) foram determinadas através do produto das intensidades pelos respectivos tempos de infiltração (em hora).

As vazões foram determinadas por meio do Método Racional (Equação 2). O cálculo do volume de entrada ( $V_{E}$ ) (III) é fornecido pelo produto da vazão pelo tempo (Equação 3).

$\mathrm{Q}=\frac{\mathrm{C} \cdot \mathrm{i} \cdot \mathrm{A} \cdot 10^{-3}}{3600}$

Eq. 2

$\mathrm{V}_{\mathrm{E}}=\mathrm{Q} \cdot \mathrm{t}$

Eq. 3

Sendo:

$\mathrm{Q}=$ vazão máxima $\left[\mathrm{L}^{3 / T}\right], \mathrm{m}^{3} / \mathrm{s}$;

$\mathrm{C}=$ coeficiente de escoamento (adimensional);

$\mathrm{i}=$ intensidade da precipitação $[\mathrm{L} / \mathrm{T}], \mathrm{mm} / \mathrm{h}$;

$\mathrm{A}=$ área do telhado $\left[\mathrm{L}^{2}\right], \mathrm{m}^{2}$;

$\mathrm{V}_{\mathrm{E}}=$ volume de entrada $\left[\mathrm{L}^{3}\right], \mathrm{m}^{3} ; \mathrm{e}$

$\mathrm{t}=$ tempo [T], segundos.

O volume de saída (IV) de uma estrutura de infiltração é determinado a partir da superfície de infiltração.

Este trabalho adotou a hipótese de que a infiltração ocorre pelo fundo e pela metade da altura das paredes da camada de armazenamento do jardim de chuva piloto. Considerou-se que, após a passagem da água da superfície para o interior do jardim de chuva piloto, a camada de armazenamento reteve temporariamente a água infiltrada, concomitantemente a sua distribuição no fundo e nas laterais da estrutura.
Assim, o volume de saída foi determinado a partir dos ensaios de infiltração, utilizando a metodologia Beerkan descrita em Lassabatère et al. (2006) e em Souza et al. (2008).

Para os ensaios de infiltração foi utilizado o método do infiltrômetro de anel simples (diâmetro de $15 \mathrm{~cm}$ ). O valor da lâmina acumulada nos ensaios foi de $13,58 \mathrm{~cm}$. O volume de saída é representado pelo produto da lâmina infiltrada acumulado no tempo t pela área de infiltração do experimento (Equação 4). O volume de saída foi de $0,5432 \mathrm{~m}^{3}(543,2 \mathrm{~L})$.

$\mathrm{V}_{\mathrm{SAÍDA}}=\mathrm{A}_{\text {infiltração }} \cdot \mathrm{I}_{\text {acumulada }}$

Eq. 4

Sendo:

$\mathrm{V}_{\text {SAÍDA }}=$ volume de saída $\left[\mathrm{L}^{3}\right], \mathrm{m}^{3}$;

$A_{\text {infiltração }}=$ área de infiltração $\left[\mathrm{L}^{2}\right], \mathrm{m}^{2}$; e

$\mathrm{I}_{\text {acumulada }}=$ infiltração acumulada [L], metros.

A camada de brita foi calculada para que a dimensão de altura fosse suficiente para armazenar temporariamente o volume de água infiltrado para o tempo de retorno de 5 anos e uma duração de chuva de projeto de $15 \mathrm{~min}$, valores adotados em obras de microdrenagem.

Para determinar a altura da camada de armazenamento (V), adotou-se a Equação 5.

$H b=\left(C \cdot I \cdot A \cdot t \cdot\left(10^{\wedge}(-3) / 3600\right)-I a c \cdot B \cdot L-I a c \cdot L \cdot\right.$ $h a-I a c \cdot B \cdot h a-h a \cdot B \cdot L \cdot \eta a) /(B \cdot L \cdot \eta b+I a c \cdot L+$ Iac $\cdot B$ )

Eq. 5

Sendo:

$\mathrm{H}_{\mathrm{b}}=$ altura de brita $[\mathrm{L}]$, metros; 
$h_{a}=$ altura da camada de areia [L], metros;

$\mathrm{C}=$ coeficiente de escoamento (adimensional);

$\mathrm{I}=$ intensidade da precipitação[L/T], $\mathrm{mm} / \mathrm{h}$;

$\mathrm{A}=$ área do telhado $\left[\mathrm{L}^{2}\right], \mathrm{m}^{2}$;

$\mathrm{t}=$ tempo do ensaio de infiltração [T], segundos;

$\mathrm{B}$ e $\mathrm{L}=$ largura e comprimento da base do experimento[L], metros;

$\mathrm{I}_{\mathrm{ac}}=$ infiltração acumulada [L];

$\eta_{\mathrm{A}}=$ porosidade da areia (adimensional);

$\eta_{\mathrm{B}}=$ porosidade da brita (adimensional);

Aaltura da camada de armazenamento (brita) foi de $0,65 \mathrm{~m}(65 \mathrm{~cm})$. Adicionou-se à camada de brita uma margem de segurança para armazenamento equivalente a $5 \mathrm{~cm}$ de altura. Assim, a camada de armazenamento do jardim de chuva piloto ficou com uma altura total de $0,70 \mathrm{~m}(70 \mathrm{~cm})$.

\section{Modelagem e validação de modelos teóricos de Infiltração}

Visando representar a capacidade de infiltração da superfície do jardim e compará-la com o potencial de infiltração do solo natural, ajustaram-se os modelos de Horton (1940) (Equações 6 e 7) e Mezencev (PHILIP, 1957) (Equações 8 e 9) aos dados experimentais obtidos.

$\mathrm{i}_{\mathrm{t}}=\mathrm{I}_{\mathrm{f}}+\left(\mathrm{I}_{\mathrm{i}}-\mathrm{I}_{\mathrm{f}}\right) \mathrm{e}^{-\mathrm{xt}}$

Eq. 6

Sendo:

$\mathrm{I}=\mathrm{I}_{\mathrm{f}} \cdot \mathrm{t}+\left(\mathrm{I}_{\mathrm{i}}-\mathrm{I}_{\mathrm{f}}\right) \cdot\left(\frac{1-\mathrm{e}^{-\mathrm{xt}}}{x}\right)$

Sendo:

$\mathrm{I}_{\mathrm{t}}=$ taxa de infiltração $[\mathrm{L} / \mathrm{T}], \mathrm{mm} / \mathrm{h}$;

I = lâmina infiltrada [L], mm;

$\mathrm{I}_{\mathrm{f}}=$ taxa de infiltração final ou velocidade básica de infiltração [L/T], mm/h;

$\mathrm{I}_{\mathrm{i}}=$ taxa de infiltração inicial $[\mathrm{L} / \mathrm{T}], \mathrm{mm} / \mathrm{h}$;

$\mathrm{t}=\mathrm{o}$ tempo no instante $\mathrm{t}[\mathrm{T}]$, horas; e

$\mathrm{x}=$ constante de decaimento $\left[\mathrm{T}^{-1}\right], \mathrm{h}^{-1}$.

$I_{t}=I_{f}+\alpha \cdot t^{-\beta}$

Eq. 8

$I_{t}=I_{f} t+\frac{\alpha}{1-\beta} \cdot t^{(1-\beta)}$

Eq. 9

Sendo:

$\mathrm{I}_{\mathrm{t}}=$ taxa de infiltração $[\mathrm{L} / \mathrm{T}], \mathrm{mm} / \mathrm{h}$;

$\mathrm{I}_{\mathrm{t}}=$ lâmina infiltrada [L], mm;

$\mathrm{I}_{\mathrm{f}}=$ taxa de infiltração final ou velocidade básica de infiltração [L/T], mm/h;

$\alpha=$ constante empírica, com $(0<\alpha<1)$; $\beta=$ constante empírica, $\operatorname{com}(0<\beta<1)$; e

$\mathrm{t}=$ tempo $[\mathrm{T}]$, horas.

Os parâmetros de cada equação foram obtidos utilizando-se a técnica de otimização, com o auxílio da ferramenta Solver, da Microsoft, Office Excel, minimizando a função $\mathrm{F}(\mathrm{v})$, conforme a Equação 10.

$\mathrm{F}(\mathrm{v})=\sum_{\mathrm{i}=1}^{\mathrm{N}}\left[\mathrm{I}_{\left(\mathrm{t}_{\mathrm{i}}\right)}-\mathrm{I}^{\wedge}\left(\mathrm{t}_{\mathrm{i}}{ }^{\wedge}, \mathrm{v}\right)\right]^{2}$

Eq. 10

Sendo:

I(ti) um conjunto de valores medidos em tempos específicos ti $(\mathrm{i}=1,2, \ldots \mathrm{N})$; e

I^ (ti^, v) o conjunto de valores calculados pelo modelo com a otimização de um vetor de valores de parâmetros $\mathrm{v}=\left\{\mathrm{I}_{\mathrm{f}}, \mathrm{I}_{\mathrm{i}}, \mathrm{S}, \beta, \alpha\right\}$.

Para os parâmetros $\alpha$ e $\beta$ da equação de Mezencev foram utilizadas as seguintes restrições: $(0<\alpha<1)$ e $(0<\beta<1)$.

A fim de validar os parâmetros adotados e obtidos para os dois modelos (Horton e Mezencev), foram utilizadas as ferramentas coeficiente de determinação, razão de desvios e coeficiente de massa residual, conforme Willmott et al. (1985).

$\mathrm{O}$ coeficiente de massa residual (CMR) reflete a superestimativa $(\mathrm{CMR}<0)$ ou subestimativa (CMR > 0) com relação aos valores obtidos experimentalmente. $\mathrm{Na}$ ausência de desvios sistemáticos entre os valores observados e calculados, o valor esperado tende a zero (WILLMOTT et al., 1985) (Equação 11).

$\mathrm{CRM}=\left(\frac{\Sigma \mathrm{Mi}-\Sigma \mathrm{Ei}}{\Sigma \mathrm{Mi}}\right)$

Eq. 11

A razão de desvios (RD) (Equação 12) é definida como a razão entre a dispersão dos valores observados e os calculados pelo modelo, e tende a 1 (um) quando há igualdade entre os valores observados e os calculados (WILLMOTT et al., 1985).

$\mathrm{RD}=\frac{\Sigma(\mathrm{Mi}-\overline{\mathrm{M}})^{2}}{\Sigma(\mathrm{Ei}-\overline{\mathrm{M}})^{2}}$

Eq. 12

O coeficiente de determinação $\left(\mathrm{R}^{2}\right)$ indica a proporção da variância nos valores calculados no modelo (Equação 13). Quanto mais próximo da unidade for esse coeficiente, maior será a validade da regressão:

$\mathrm{R}^{2}=\frac{[\mathrm{n} \cdot(\Sigma \mathrm{Mi} \cdot \mathrm{Ei})-\Sigma \mathrm{Mi} \cdot \Sigma \mathrm{Ei}]^{2}}{\mathrm{n} \cdot\left[\Sigma \mathrm{Ei}^{2}-(\Sigma \mathrm{Ei})^{2}\right]\left[\mathrm{n} \cdot \Sigma \mathrm{Mi}^{2}-(\Sigma \mathrm{Mi})^{2}\right]}$

Eq. 13

Sendo:

$\mathrm{M}_{\mathrm{i}}=$ corresponde aos valores calculados pelo modelo;

$\mathrm{E}_{\mathrm{i}}=$ valores observados nos experimentos; 
$\mathrm{n}=$ quantidade de valores obtidos no experimento e no modelo.

Sendo:

$\overline{\mathrm{M}}=$ corresponde à média dos valores calculados.

Foram gerados cenários de lâminas escoadas para cada um desses solos utilizando-se chuvas para tempos de retorno de $2,5,10$ e 25 anos e para duração de 30,45 e 60 min.

\section{Instalação do experimento}

O jardim de chuva piloto foi instalado a uma profundidade de $1 \mathrm{~m}$ e composto de cinco camadas, iniciando-se de baixo para cima (Figura 4):

(a) areia - $10 \mathrm{~cm}$-filtro natural para as águas infiltradas no sistema;

(b) brita $-70 \mathrm{~cm}$ - facilita o movimento da água no sistema e desempenha a função de armazenamento para as águas infiltradas no experimento. A brita utilizada é do tipo $19 \mathrm{e}$ apresenta porosidade de $52 \%$;

(c) manta geotêxtil - geomembrana para retenção de finos e filtração primária das águas;

(d) substrato - $10 \mathrm{~cm}$ - mistura composta de terra preta e húmus de minhoca, na mesma proporção (1:1). O topo da camada do substrato fica $10 \mathrm{~cm}$ abaixo do nível do solo existente, formando uma lâmina d'água retida na superfície do experimento, para posterior infiltração;

(e) cobertura vegetal - dispostas no local onde fica a retenção da água, devido à diferença de altura em relação à superfície do solo. Foram utilizadas plantas adaptáveis às condições climáticas locais, rústicas e popularmente conhecidas, ixora-vermelha (Ixorachinensis) e írisamarela (Iris pseudacorus).

O monitoramento da precipitação foi registrado por um pluviômetro automático instalado a uma distância de 1,50 m do solo e a 2,80 m do jardim de chuva piloto, livre de qualquer obstrução.

A quantificação do volume de entrada no experimento foi determinada pelo volume precipitado diretamente sobre a área do experimento, somado ao volume produzido pelo escoamento superficial do telhado. Realizou-se uma proteção no entorno do jardim de chuva piloto, evitando a contribuição do escoamento superficial das áreas adjacentes.

Para direcionar as águas do telhado ao jardim de chuva piloto, instalou-se um conjunto para a captação das águas superficiais, formado por uma calha metálica abaixo da calha de concreto existente e por um tubo de queda direcionado ao experimento (Figura 5).

O monitoramento dos níveis de água armazenados no interior do experimento foi registrado por um sensor de nível automático, adotando intervalos de leitura a cada minuto.Instalou-se o equipamento em um piezômetro, alcançando a profundidade de $1 \mathrm{~m}$.

\section{Análise de custo}

Realizou-se uma análise de custo do jardim de chuva piloto utilizando-se preços característicos da cidade do Recife baseados na Tabela de Preços para Contratação de Obras e Serviços de Engenharia da Empresa de Manutenção e Limpeza Urbana da Prefeitura de Recife para 2011 (EMLURB, 2011).

O estudo de custo visa determinar a importância dos recursos necessários para a construção da técnica do jardim de chuva, verificando-se a sensibilidade do preço de construção em função dos tempos de retorno (2, 5, 10 e 25 anos) e dos tempos de duração da chuva de projeto $(5,15,60 \mathrm{e}$ $120 \mathrm{~min})$.

O intervalo de tempos de retorno de 2 a 10 anos foi utilizado por compreender a faixa recomendada para o dimensionamento de estruturas de microdrenagem. O tempo de retorno de 25 anos foi utilizado com o objetivo de extrapolar os resultados e verificar qual é o incremento no custo resultante dessa extrapolação.

Foram considerados os custos dos itens presentes na Tabela 2, em que constam as descrições e os valores dos materiais e serviços utilizados na construção do experimento, para uma chuva de tempo de retorno de 25 anos proveniente de uma área de drenagem de $74,80 \mathrm{~m}^{2}$. 
Figura 4 - Dimensões adotadas no jardim de chuva piloto apresentadas em planta baixa (a) e em perfil (b), e uma vista tridimensional da estrutura (c)

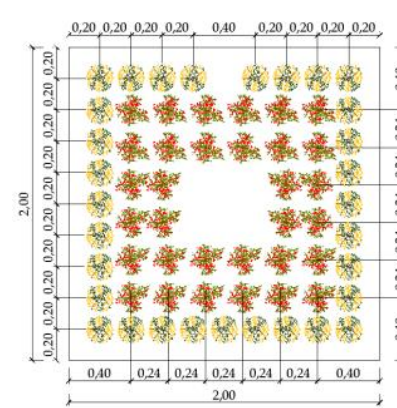

(a)

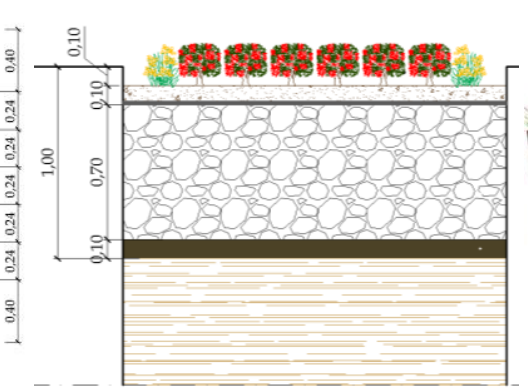

(b)

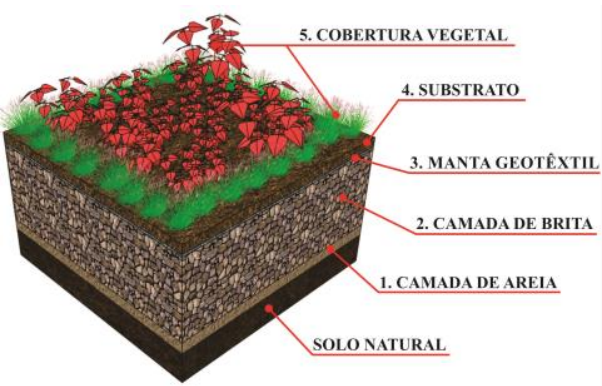

(c)

Figura 5 - Conjunto para captação das águas superficiais do telhado para o jardim de chuva piloto da UFPE

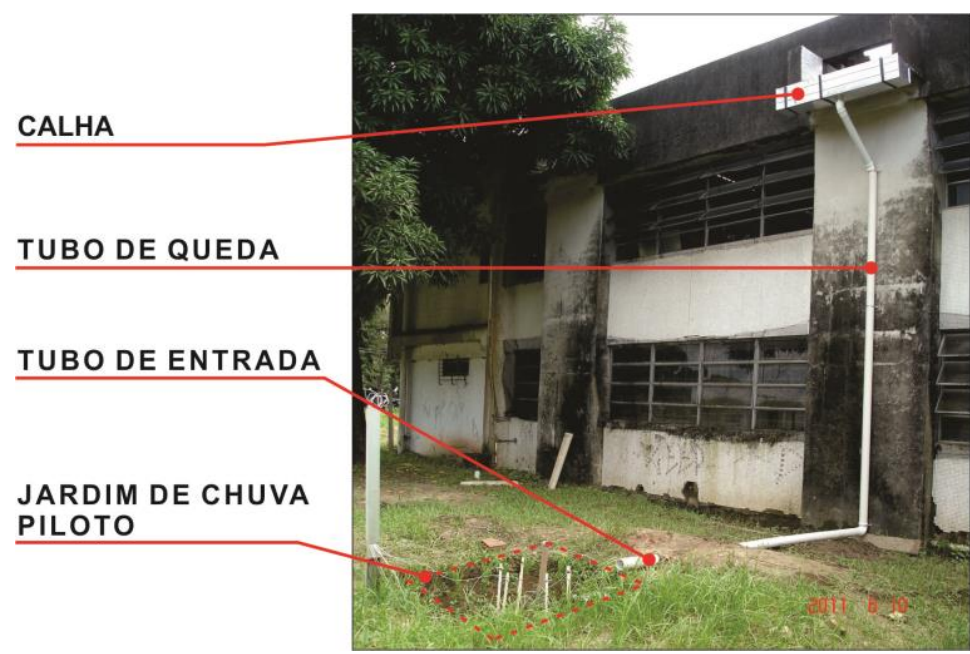

Tabela 2 - Valor da construção do jardim de chuva piloto da UFPE, com base na Emlurb (2011) para uma chuva de tempo de retorno de 25 anos proveniente de uma área de drenagem de 74,80 $\mathrm{m}^{2}$

\begin{tabular}{c|c|c|c|c}
\hline \multicolumn{2}{c|}{ Emlurb (2011) } & \multicolumn{2}{c}{ Jardim de chuva piloto } \\
\hline Item & Unidade & Valor unitário (R\$)* & Quantidade & Custo (R\$)* \\
\hline Escavação & $\mathrm{m}^{3}$ & 14,23 & 4 & 56,92 \\
Areia & $\mathrm{m}^{3}$ & 38,42 & 0,4 & 15,36 \\
Brita & $\mathrm{m}^{3}$ & 71,18 & 2,80 & 199,30 \\
Geotêxtil & $\mathrm{m}^{2}$ & 5,39 & 4,00 & 21,56 \\
Substrato & $\mathrm{m}^{3}$ & 57,00 & 0,4 & 22,80 \\
Mudas & Unidade & 2,90 & 63 & 182,70 \\
\hline \multicolumn{2}{l}{ Sistema de captação das águas pluviais (calha, tubos e conexões) } \\
\multicolumn{2}{l}{ Valor total da construção do jardim de chuva piloto da UFPE } \\
\hline
\end{tabular}

Nota: *Valores dados em reais para 2011 ; e ${ }^{* *}$ Calha de alumínio de $183 \mathrm{~cm}$ de comprimento e $30 \mathrm{~cm}$ de largura e altura.

Assim, foi utilizada a Equação 14 para o cálculo do custo total do jardim de chuva:

$\mathrm{C}_{(\mathrm{t}, \mathrm{Tr})}=\mathrm{C}_{\mathrm{B}}$. L. B. $\mathrm{H}_{(\mathrm{t}, \mathrm{Tr})}+\mathrm{C}_{\mathrm{E}}\left(\mathrm{H}_{(\mathrm{t}, \mathrm{Tr})}+\mathrm{H}_{\mathrm{a}}+\right.$ $\left.\mathrm{H}_{\mathrm{L}}\right)+\mathrm{C}_{\mathrm{A}} \cdot$ B. L. $\mathrm{H}_{\mathrm{a}}+\mathrm{C}_{\mathrm{GE}} \cdot \mathrm{B} \cdot \mathrm{L}+\mathrm{C}_{\mathrm{M}} \cdot \mathrm{Q}_{\mathrm{M}}$

Eq. 14
$\mathrm{C}_{(\mathrm{t}, \mathrm{Tr})}=$ custo do jardim de chuva associado a uma duração t e a um tempo de retorno $\mathrm{Tr},[\mathrm{R} \$]$;

$\mathrm{C}_{\mathrm{B}}=$ custo por metro cúbico do material para a camada de armazenamento $\left[\mathrm{R} \$ / \mathrm{m}^{3}\right]$;

$\mathrm{C}_{\mathrm{E}}=$ custo por metro cúbico da escavação, já incluídos material e mão de obra $\left[\mathrm{R} \$ / \mathrm{m}^{3}\right]$;

Sendo: 
$\mathrm{C}_{\mathrm{A}}=$ custo por metro cúbico do material para a camada de armazenamento $\left[\mathrm{R} \$ / \mathrm{m}^{3}\right]$;

$\mathrm{C}_{\mathrm{GE}}=$ custo por metro quadrado do geotêxtil $\left[\mathrm{R} \$ / \mathrm{m}^{2}\right]$;

$\mathrm{C}_{\mathrm{M}}=$ custo da quantidade de mudas por metro quadrado $\left[\mathrm{R} \$ / \mathrm{m}^{2}\right]$

$\mathrm{H}_{(\mathrm{t}, T \mathrm{~T}, \mathrm{~A})}=$ altura da camada de armazenamento do jardim de chuva, associado a uma área de drenagem A, duração t e a um tempo de retorno $\mathrm{Tr}$, [m];

$\mathrm{H}_{\mathrm{a}}=$ espessura da camada de areia do jardim de chuva associado a uma duração t e a um tempo de retorno $\mathrm{Tr}$, metros;

$\mathrm{H}_{\mathrm{L}}=$ espessura da camada livre do jardim de chuva, metros; e

$\mathrm{Q}_{\mathrm{M}}=$ quantidade de mudas por metro quadrado [Unit/m²].

\section{Resultados}

\section{Análises de sensibilidade do dimensionamento}

Na Figura 6 é observada a espessura da camada de armazenamento necessária para tempos de retorno de $2,5,10$ e 25 anos e para precipitações com durações de até $120 \mathrm{~min}$. As curvas apresentam tendência sempre crescente, uma vez que a capacidade de armazenamento necessária cresce com o aumento da duração da precipitação.
A diferença entre as curvas, ou melhor, a diferença entre as espessuras mínimas requeridas para uma mesma duração e tempos de retorno diferentes é demonstrada na Figura 7. Para durações de até 10 min, observa-se que a diferença entre as espessuras de agregado graúdo atinge $19 \%$ quando se comparam os tempos de retorno de 2 e 5 anos; $16,5 \%$ para os tempos de retorno de 25 e 10 anos; e $13 \%$ para os tempos de retorno de 10 e 5 anos. Para todos os casos, a diferença entre as espessuras da camada de armazenamento diminui e atinge um valor constante.

Por exemplo, a escolha do tempo de retorno de 25 anos em vez de um tempo de retorno de 10 anos provoca aumento da camada de armazenamento de, no máximo, $16,5 \%$ e de, no mínimo, $12 \%$. Consequentemente, o risco de falha no dimensionamento reduz em função da concepção de uma estrutura para suportar, teoricamente, precipitações de maiores magnitudes.

A importância dessa observação se dá na fase preliminar da escolha do risco do projeto, uma vez que todo projeto de drenagem urbana necessariamente possui um risco de falha, o qual está associado ao tempo de retorno.

Essa análise do ponto de vista do risco de falha não significa que não devam ser atendidos os limites financeiros, já que, dependendo do volume construído, um aumento de $13 \%$ na espessura de agregado graúdo pode significar um aumento nos limites de orçamento.

Figura 6 - Espessura da camada de armazenamento do jardim de chuva piloto para tempos de retorno 2, 5, 10 e 25 anos e para durações de até $2 \mathrm{~h}$ (área de base de $4 \mathrm{~m}^{2}$ )

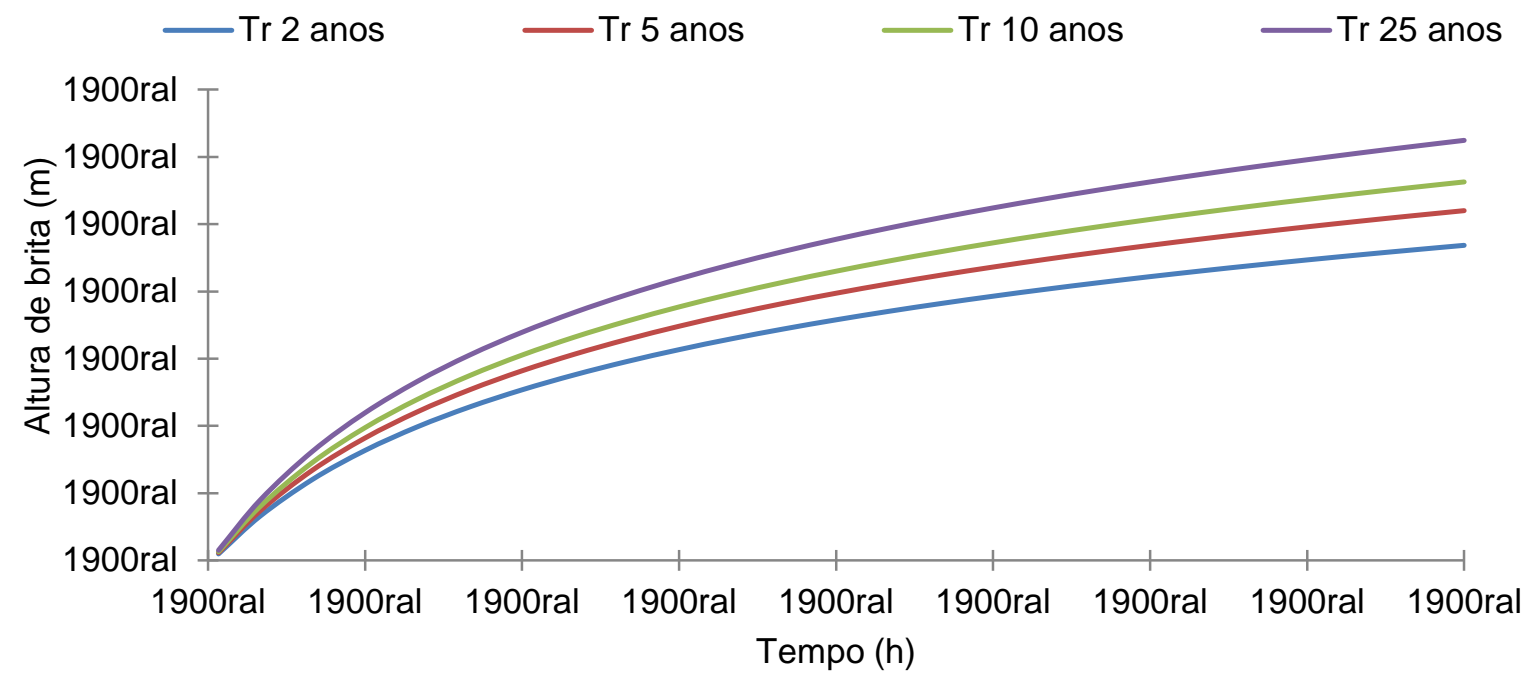

156 Melo, T. dos A. T. de; Coutinho, A. P.; Cabral, J. J. da S. P.; Antonino, A. C. D.; Cirilo, J. A. 
Figura 7- Diferenças percentuais entre as espessuras da camada de armazenamento obtidas comparação do tempo de retorno de 5 e 2 anos, do tempo de retorno de 10 e 5 anos e do tempo de retorno de 25 e 10 anos

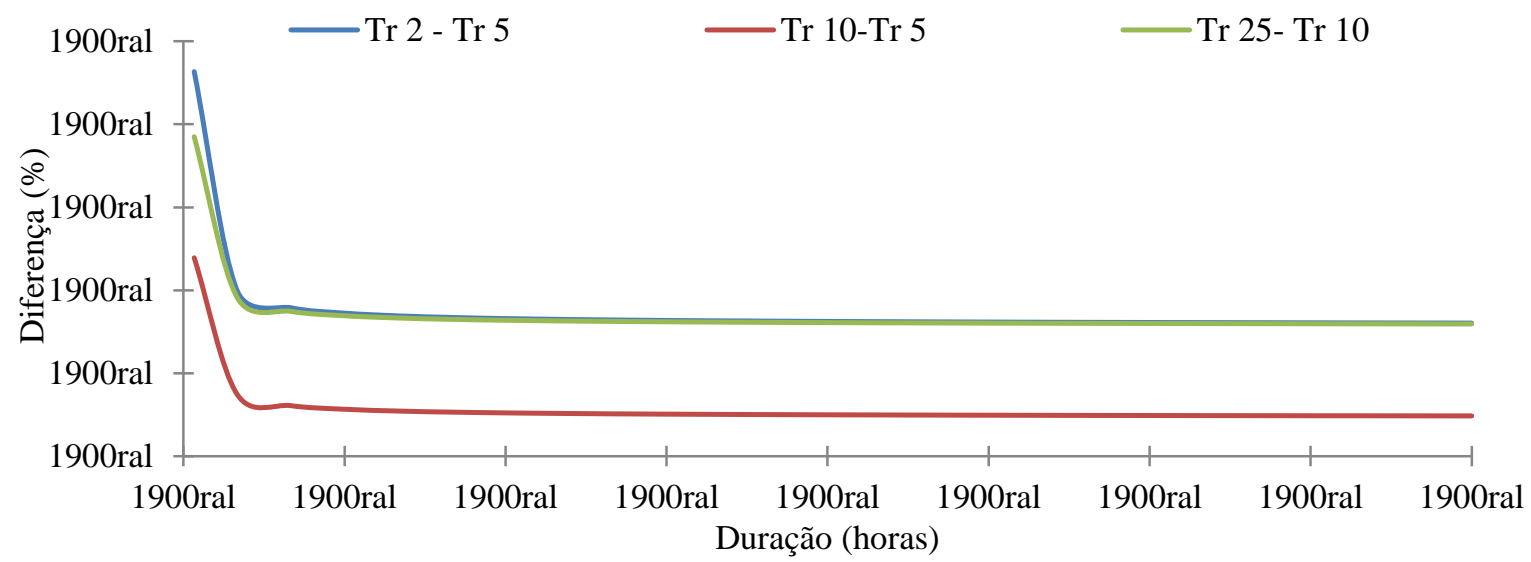

Figura 8 - Espessura da camada de armazenamento do jardim de chuva piloto (h), para tempos de retorno 2 (h2), 5 (h5), 10 (h10) e 25 (h25) anos e para durações de até 2 h. Espessuras obtidas fixando-se uma área de base de $40 \mathrm{~m}^{2}$

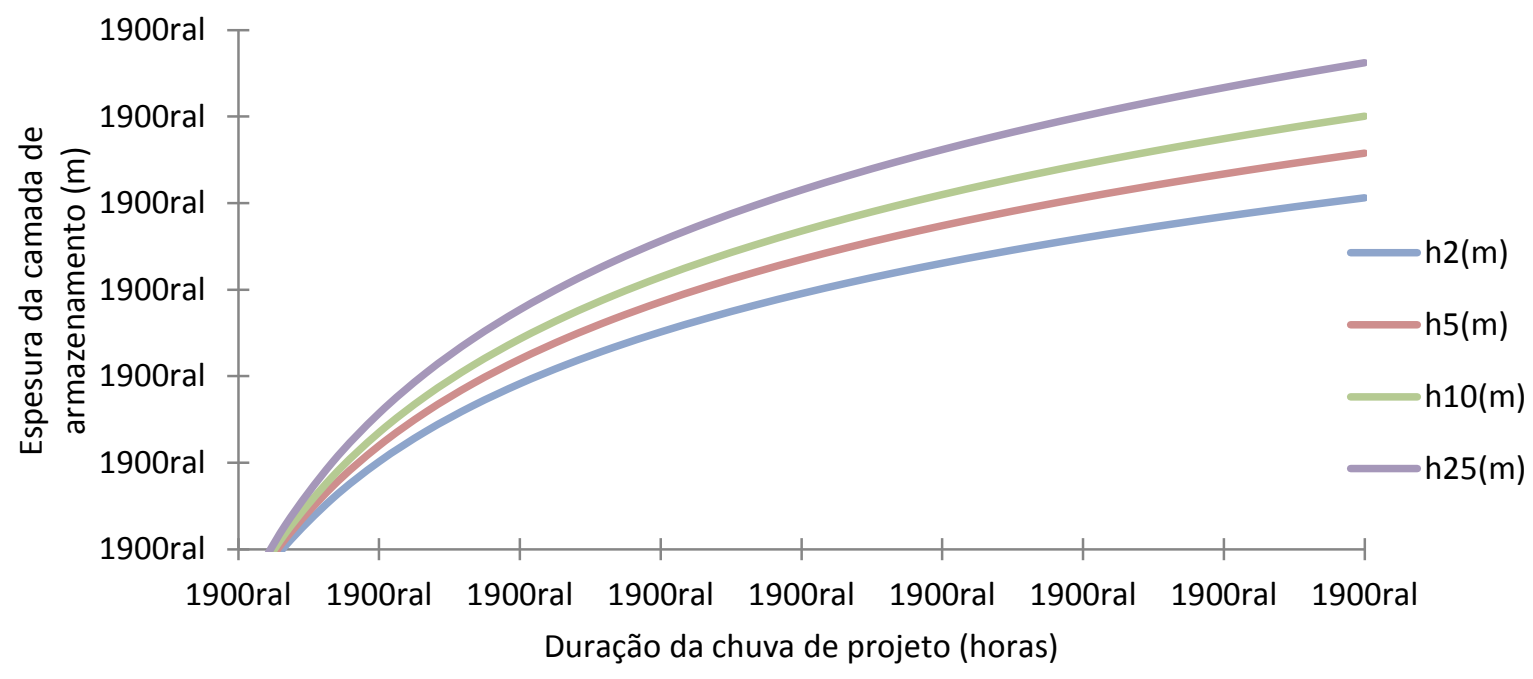

Visando observar a sensibilidade da metodologia do dimensionamento, foram determinadas as curvas da espessura da camada de armazenamento para os mesmos intervalos de tempo de retorno e duração da precipitação, fixando a área da base de infiltração em 10 vezes maior que a utilizada no experimento. Dessa maneira, a Figura 8 demonstra as espessuras obtidas, que apresentam espessura máxima de $25 \mathrm{~cm}$ para o tempo de retorno de 10 anos e uma chuva de $2 \mathrm{~h}$. Isso representa uma contribuição como alternativa de dimensionamento para jardins públicos, os quais, em geral, apresentam maiores dimensões que aquelas utilizadas no jardim de chuva piloto descrito neste trabalho. Além disso, aumentando a área do jardim de chuva piloto em 10 vezes para uma mesma duração, a espessura da camada de brita diminui da seguinte forma: 19,4 vezes - Tr de 2 anos; 14,5 vezes $-\operatorname{Tr}$ de 5 anos; e 13,5 vezes - $\operatorname{Tr}$ de 10 anos.

\section{Análise dos ensaios de infiltração}

No solo natural, o ensaio de infiltração realizado apresentou uma lâmina infiltrada de 130,15 mm em 11.800 s. O solo possui capacidade de infiltração inicial de $327,5 \mathrm{~mm} / \mathrm{h}$, decaindo para um valor aproximadamente igual à condutividade hidráulica saturada de $37,94 \mathrm{~mm} / \mathrm{h}$.

O ajuste aos modelos de Horton e Mezencev (Figura 9), com os dados do solo natural, apresentou bom desempenho (coeficiente de determinação $\left[\mathrm{R}^{2}\right]$ igual a 0,994 para Horton e a 0,998 para Mezencev). 
Através desse ajuste foram determinados os parâmetros $\left(\mathrm{I}_{\mathrm{i}}, \mathrm{I}_{\mathrm{f}}\right.$ e x) para Horton e os parâmetros $\alpha, \beta$ e if para Mezencev (Tabela 3). Observou-se que o modelo de Mezencev apresentou melhor desempenho estatístico que o modelo de Horton.

A camada superficial do jardim de chuva piloto apresentou uma lâmina infiltrada acumulada de $497,97 \mathrm{~mm}$ ao final do ensaio em um tempo total de 5.215 s. Além disso, observa-se que no intervalo entre os tempos de $1.290 \mathrm{~s}$ e $3.620 \mathrm{~s}$ ocorre uma mudança na concavidade da curva de infiltração, indicando um comportamento bimodal (Figura 10), diferente da evolução teórica tradicional de uma curva de infiltração.

Figura 9 - Ajuste da curva de infiltração acumulada do solo natural ao modelo de Horton e ao modelo de Mezencev

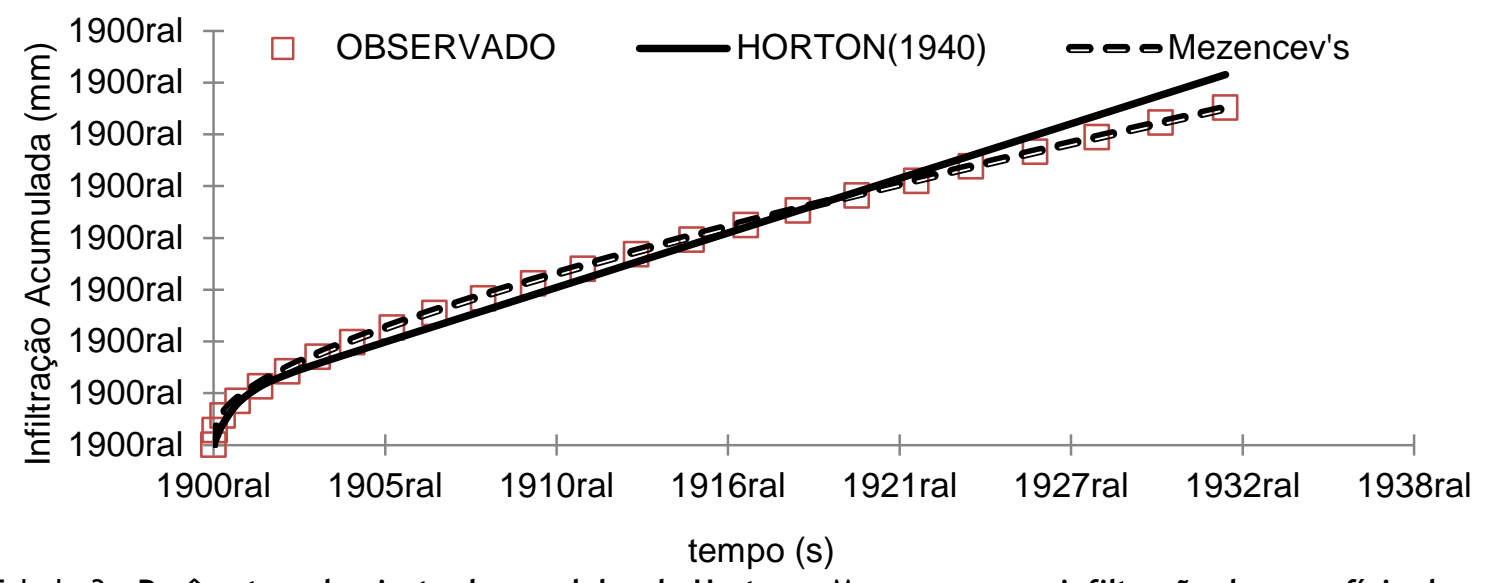

Tabela 3 - Parâmetros do ajuste dos modelos de Horton e Mezencev para infiltração da superfície do solo natural

\begin{tabular}{ccc|ccc}
\hline \multicolumn{3}{c|}{ Horton (1940) } & \multicolumn{3}{|c}{ Mezencev (PHILIP, 1957) } \\
\hline $\mathrm{I}_{\mathrm{i}}(\mathrm{mm} / \mathrm{h})$ & $\mathrm{I}_{\mathrm{f}}(\mathrm{mm} / \mathrm{h})$ & $\beta\left(\mathrm{h}^{-1}\right)$ & $\mathrm{I}_{\mathrm{f}}(\mathrm{mm} / \mathrm{h})$ & $\alpha$ & $\beta\left(\mathrm{h}^{-1}\right)$ \\
327,50 & 37,94 & 15,48 & 18,84 & 0,738 & 0,620 \\
\hline $\mathrm{R}^{2}$ & $\mathrm{RD}$ & $\mathrm{CRM}$ & $\mathrm{R}^{2}$ & $\mathrm{RD}$ & $\mathrm{CRM}$ \\
0,994 & 1,201 & 0,026 & 0,999 & 1,025 & 0,012 \\
\hline
\end{tabular}

Figura 10 - Ajuste da curva de infiltração acumulada do solo da primeira camada do jardim aos modelos de Horton e Mezencev

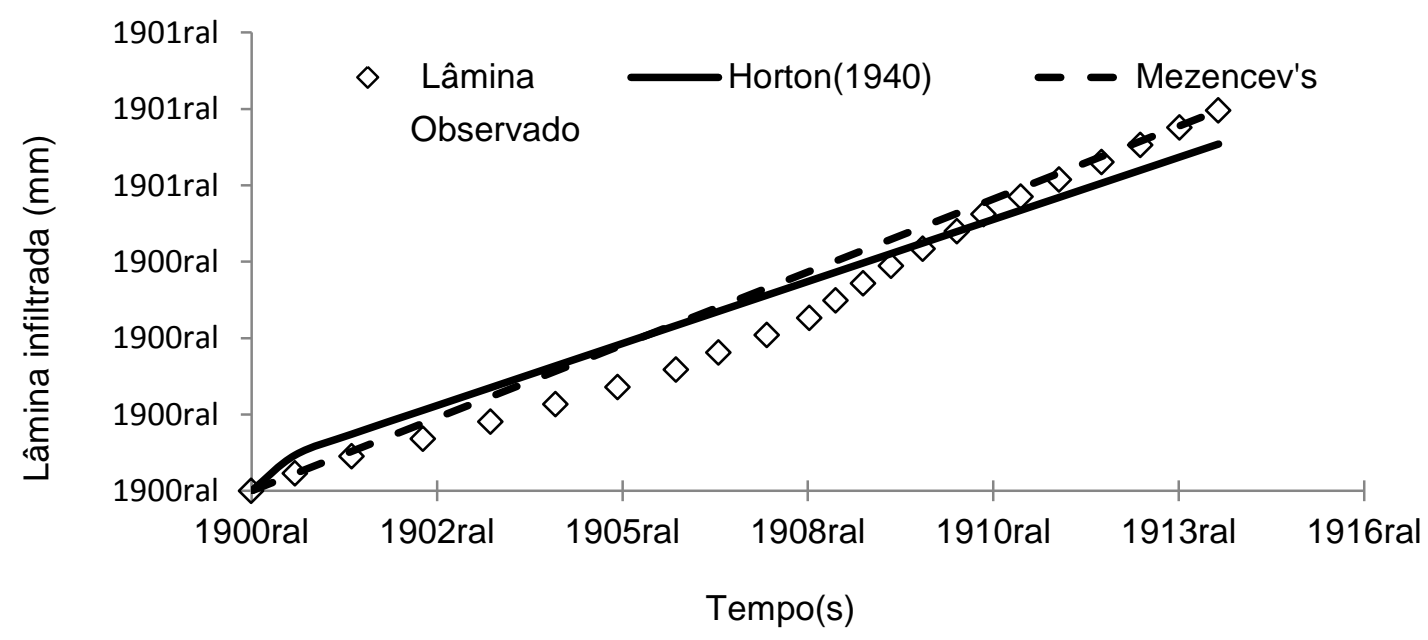

158 Melo, T. dos A. T. de; Coutinho, A. P.; Cabral, J. J. da S. P.; Antonino, A. C. D.; Cirilo, J. A. 
Essa mudança na velocidade de infiltração pode ser explicada pelo efeito da matéria orgânica, que age retendo água nesse intervalo de tempo (BRANDÃO, 2006), que, no caso do jardim de chuva piloto, apresenta um percentual de $37,85 \%$, ou da hidrofobia do solo (CLOTHIER; VOGELER; MAGESAN, 2000).

A Tabela 4 mostra o bom desempenho dos modelos de Horton e Mezencev para a infiltração na superfície do jardim de chuva piloto. Os valores dos parâmetros obtidos para a camada superior do jardim de chuva piloto no modelo de Horton indicam elevadas taxas de infiltrações iniciais e finais, o que também pode ser observado a partir do parâmetro $i_{\mathrm{f}}$ da equação de Mezencev.

No tocante aos dois ensaios de infiltração realizados na superfície do jardim de chuva piloto, os resultados apresentaram grande variabilidade nos valores.

No estudo realizado por Jenkins, Wadzuk e Welker (2010), as taxas de infiltração dos jardins de chuva em estudo também apresentaram considerável variabilidade. Apesar de o solo natural ser do tipo silte arenoso (58\% de silte e $42 \%$ de areia), a superfície do jardim de chuva foi modificada, a fim de aumentar a capacidade de infiltração com relação ao solo natural. Foi inserida uma mistura permeável composta de $71 \%$ de areia e $29 \%$ de silte. Mesmo nos ensaios realizados em anos diferentes, as taxas de infiltração ainda mantiveram a variabilidade.
A Tabela 5 apresenta a variabilidade das taxas de infiltração de Jenkins, Wadzuk e Welker (2010), e do jardim de chuva piloto deste estudo. Apesar de os tipos de solos naturais serem diferentes, a estrutura superficial de ambos foi modificada, para potencializar a infiltração nos experimentos, apresentando um aspecto comum entre os estudos. Todas as taxas apresentadas são as máximas medidas em cada ensaio realizado.

Esse aspecto mostra que o aumento e a variabilidade da infiltração das águas no solo dependem mais da estrutura e da composição de solo permeável inserida no jardim de chuva do que do tipo de solo urbano natural existente.

Emerson e Traver (2008) afirmam que essas variações não são incomuns, mesmo que os ensaios sejam realizados pouco distantes entre si. A diversidade na composição do solo pode criar caminhos preferenciais em determinados pontos do experimento. Pode haver acumulação de materiais carreados pelo escoamento superficial, que podem se concentrar em um local específico.

Devido à variabilidade nas taxas de infiltração do jardim de chuva piloto, foi adotada uma taxa de infiltração média de $312 \mathrm{~mm} / \mathrm{h}$, como referência na análise do comportamento do processo de infiltração no experimento.

Esse valor insere essa camada em solos com classificação hidrológica do tipo A do Soil Conservetion Service (SARTORI; GENOVEZ; LOMBARDI NETO, 2005a, 2005b; SARTORI; GENOVEZ, 2011).

Tabela 4 - Parâmetros do ajuste dos modelos de Horton e Mezencev para infiltração da superfície do jardim de chuva

\begin{tabular}{ccc|ccc}
\hline & Horton (1940) & \multicolumn{3}{c}{ Mezencev (PHILIP, 1957) } \\
\hline $\mathrm{I}_{\mathrm{i}}(\mathrm{mm} / \mathrm{h})$ & $\mathrm{I}_{\mathrm{f}}(\mathrm{mm} / \mathrm{h})$ & $\beta\left(\mathrm{h}^{-1}\right)$ & $\mathrm{I}_{\mathrm{f}}(\mathrm{mm} / \mathrm{h})$ & $\alpha$ & $\beta\left(\mathrm{h}^{-1}\right)$ \\
1418,51 & 292,45 & 37,09 & 343,62 & 0,00021 & 0,998 \\
\hline $\mathrm{R}^{\mathbf{2}}$ & $\mathrm{RD}$ & $\mathrm{CRM}$ & $\mathrm{R}^{2}$ & $\mathrm{RD}$ & $\mathrm{CRM}$ \\
0,971 & 0,700 & 0,057 & 0,978 & 0,938 & 0,099 \\
\hline
\end{tabular}

Tabela 5 - Comparação da variabilidade das taxas de infiltraçãodo jardim de chuva piloto da UFPE e as de Jenkins, Wadzuk e Welker (2010)

\begin{tabular}{c|c|c|c}
\hline Experimento & Ano & \multicolumn{2}{|c}{$\begin{array}{c}\text { Taxas de } \\
\text { infiltração medidas } \\
(\mathbf{m m} / \mathbf{h})\end{array}$} \\
\hline $\begin{array}{c}\text { Jenkins, Wadzuk } \\
\text { e Welker (2010) }\end{array}$ & 2006 & 50,31 & 141,83 \\
\hline $\begin{array}{c}\text { Jardim de chuva } \\
\text { piloto }\end{array}$ & 2009 & 36,25 & 137,5 \\
\hline
\end{tabular}




\section{Análise do desempenho do jardim de chuva}

A avaliação do jardim de chuva piloto como técnica compensatória no manejo de águas pluviais foi realizada considerando-se o principal evento ocorrido no período de 11/04 a 11/07/2011.

A interpretação dos dados obtidos foi realizada relacionando-se a precipitação ao longo do dia e o nível de água armazenado no interior do jardim de chuva piloto.

Foram analisados os volumes precipitados, o volume retido na superfície do experimento, de, no máximo 400 L, e os volumes infiltrados.

No tocante ao armazenamento, foi avaliado o desempenho do jardim de chuva piloto como estrutura capaz de armazenar as águas no interior do experimento, monitorado com o sensor de nível instalado.

Considerando a porosidade de $52 \%$, relativa à camada de armazenamento (brita do tipo 19), o volume máximo de água a ser armazenado na camada de brita é de, aproximadamente, $1.400 \mathrm{~L}$ $\left(1,4 \mathrm{~m}^{3}\right)$

O evento analisado ocorreu no dia 16/06/2011. A lâmina total precipitada na quinzena antecedente foi de $58,67 \mathrm{~mm}$, e o nível de água no interior do experimento de $22 \mathrm{~cm}$. As condições de umidade durável do solo, ou seja, da água acumulada no solo, fizeram com que este não conseguisse retornar à condição de secura antes do evento selecionado.

A Figura 11a apresenta a relação existente entre o comportamento da precipitação ao longo do dia 16/06/2011 e a variação da altura da coluna d'água na camada de armazenamento.

Observa-se que, nas primeiras horas do dia, o nível da coluna d'água é basicamente constante, em uma altura de $22 \mathrm{~cm}$, devido às precipitações antecedentes. A partir das 5h00ocorre elevação do nível d'água, devido à precipitação ocorrida.

$\mathrm{O}$ rápido tempo de resposta pode ser observado a partir das $17 \mathrm{~h} 00$, quando há elevação brusca do nível, devido ao aumento da altura de precipitação nas últimas $7 \mathrm{~h}$ do dia. $\mathrm{O}$ nível passou de $8 \mathrm{~cm}$ e atingiu o máximo de $30,2 \mathrm{~cm}$, armazenando um volume de 603,12 L.

A precipitação entre $17 \mathrm{~h} 00$ e $23 \mathrm{~h} 59 \mathrm{~min}$ foi analisada de maneira mais detalhada (marcado com tracejado na Figura 11a), com a discretização da precipitação a cada 5 min (Figura 11b).
O gráfico apresenta três elevações consideráveis na altura de precipitação e o consequente aumento do nível d'água dentro da camada de armazenamento.

\section{Análise de custos}

As Figuras 12 e 13 apresentam, respectivamente, os custos para a implantação do jardim de chuva para a cidade do Recife para os tempos de retorno de $2,5,10$ e 25 anos, durações de 5, 15, 60 e 120 min e área de drenagem de $74,80 \mathrm{~m}^{2}$.

A Tabela 6 apresenta a variação do custo quando adotadas durações de chuvas de projeto de 5 e 60 min, para tempos de retornos de 2 e 25 anos

Analisando o custo por metro cúbico e considerando a duração de $60 \mathrm{~min}$, o custo para $\mathrm{Tr}$ de 25 anos é de $\mathrm{R} \$ 301,55$, e para $\mathrm{Tr}$ de 2 anos o custo é de R\$300,66. Esses valores são menores que os citados pela EPA (ENVIRONMENTAL..., $1999)$, de US\$232,37/m $(\mathrm{US} \$ 1,00=\mathrm{R} \$ 1,90)$ para jardins de chuva.

Assim, se um projetista pretende optar por um tempo de retorno maior, como escolher por $\operatorname{Tr}$ de 5 anos em vez de 2 anos, ou 25 anos em vez de 10 anos, isso resultaria em aumento do custo de aproximadamente $11 \%$. Já a escolha de um Tr de 10 anos em vez de um de 5 anos incrementaria um custo em média de $8 \%$.

\section{Conclusões}

A pesquisa aqui descrita utilizou uma técnica compensatória inovadora no país, o jardim de chuva, a qual apresentou resultados satisfatórios para a cidade de Recife. Essa técnica caracteriza uma solução em potencial para o desenvolvimento de cidades hidrologicamente sustentáveis, minimizando os efeitos inoportunos de um processo de urbanização não planejado e contribuindo para a restauração de ecossistemas urbanos.

A análise de sensibilidade do dimensionamento mostrou que um aumento de mais de $100 \%$ no tempo de retorno (de 10 para 25 anos) implica um aumento de menos de $17 \%$ na espessura da camada de armazenamento.

O custo da estrutura depende da duração da chuva de projeto e do tempo de retorno.Para uma duração de 5 min e um Tr de 2 anos o custo é de R\$ 419,64, e para um $\operatorname{Tr}$ de 25 anos o custo é de $\mathrm{R} \$ 562,61$. 
Figura 11 - Relação entre a precipitação e o nível d'água dentro da camada de armazenamento do jardim de chuva piloto da UFPE, em 16/06/2011 (a), com detalhe para o período de maior precipitação e sua dicretização a cada 5 min (b)

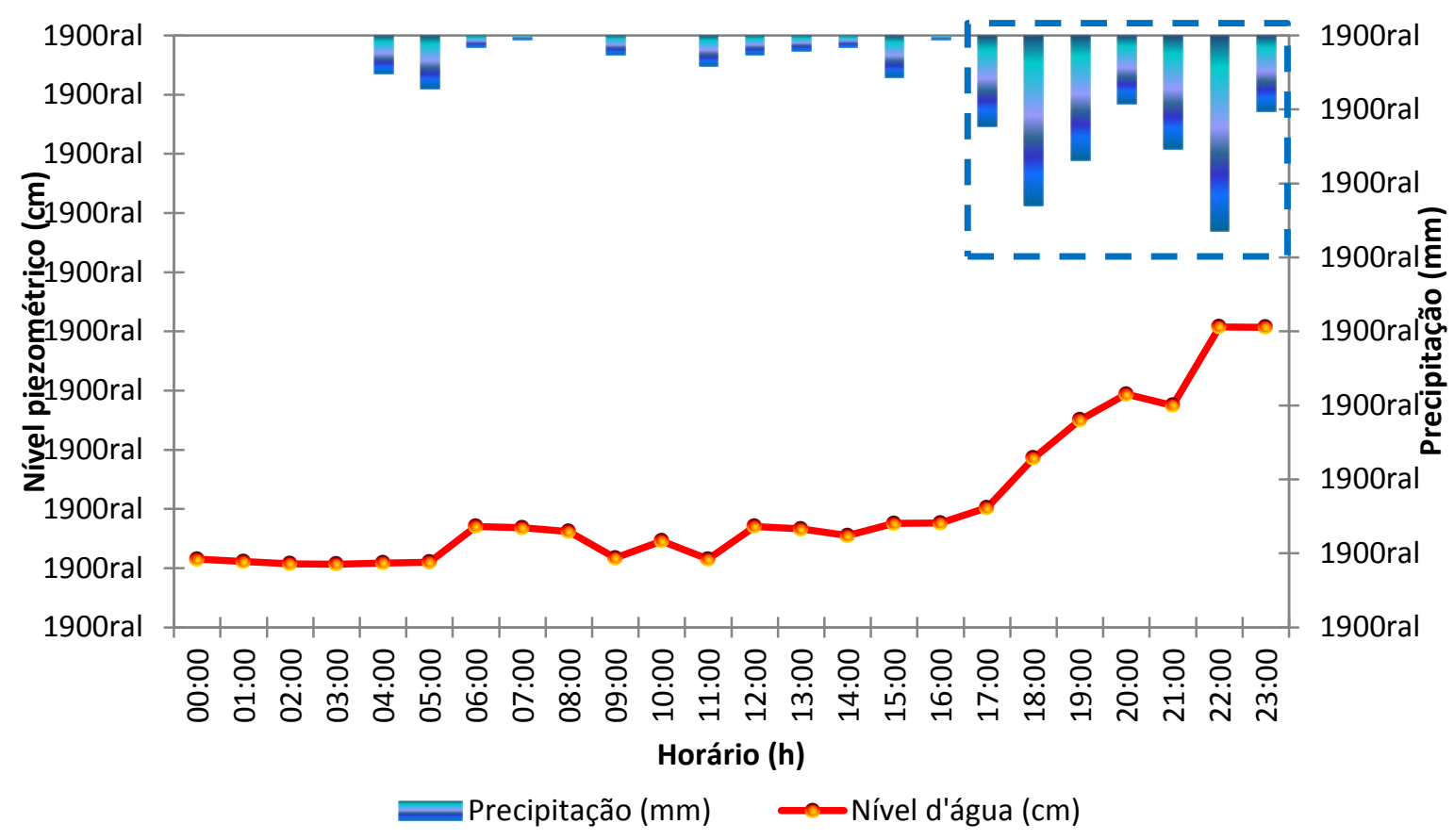

(a)

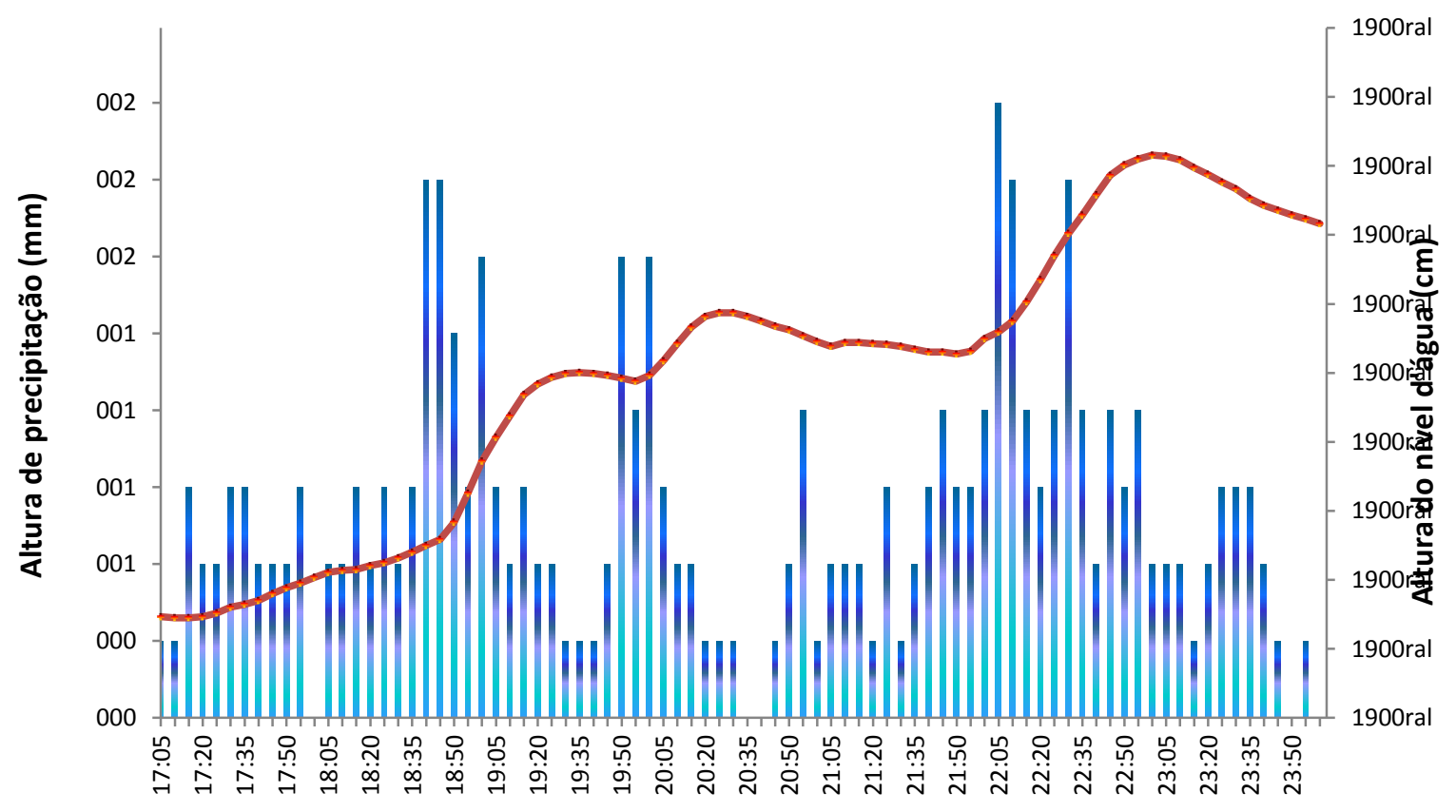

Tempo de discretização a cada 5 minutos

Precipitação - Nível

(b) 
Figura12 - Custo total do jardim de chuva para tempos de retorno de 2, 5, 10 e 25 anos e duração de 5, 15,60 e 120 min e área de drenagem de $74,80 \mathrm{~m}^{2}$

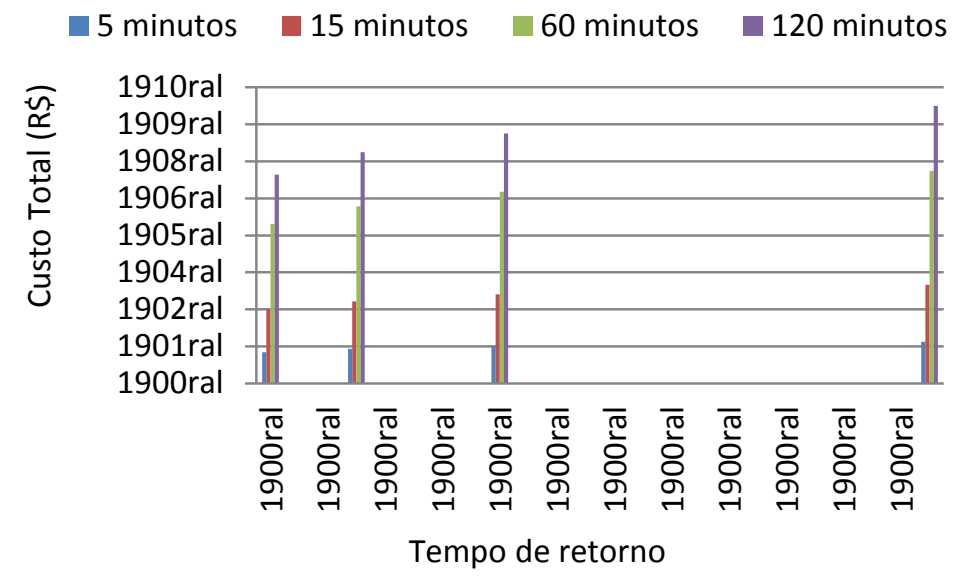

Figura 13 - Elevação do custo médio ao se aumentarem os tempos de retorno de 2 para 5 anos, de 5 para 10 anos e de 10 para 25 anos

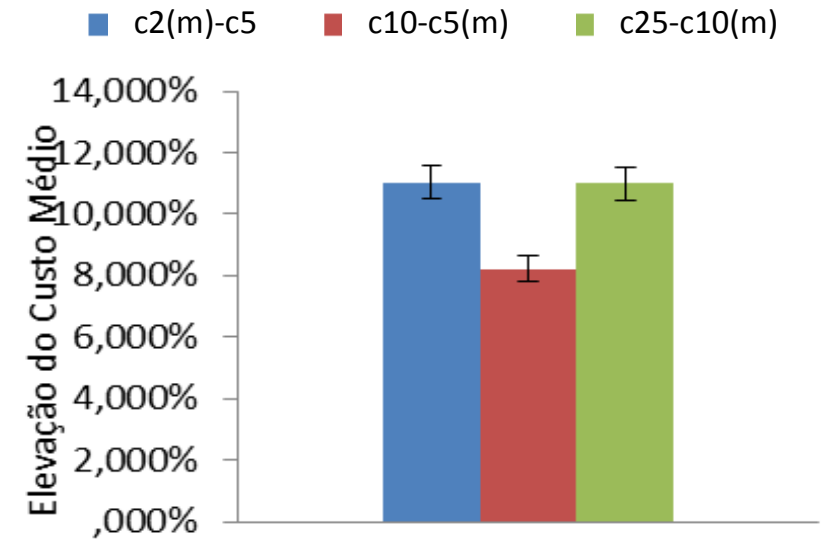

Tabela 6 - Variação do custo para durações de 5 e 60 min e tempos de retorno de 2 e 25 anos - valores para cada metro quadrado

\begin{tabular}{c|c|c}
\hline $\begin{array}{c}\text { Duração } \\
\text { (minutos) }\end{array}$ & $\begin{array}{c}\text { Tempo de } \\
\text { retorno (anos) }\end{array}$ & $\begin{array}{c}\text { Custo } \\
\left(\mathbf{R} \mathbf{\$} / \mathbf{m}^{2}\right)\end{array}$ \\
\hline \multirow{2}{*}{5} & 2 & 419,64 \\
\cline { 2 - 3 } & 25 & 562,61 \\
\hline \multirow{2}{*}{60} & 2 & $2.157,52$ \\
\cline { 2 - 3 } & 25 & $2.871,00$ \\
\hline
\end{tabular}

Mesmo para grandes volumes de precipitação, o jardim de chuva piloto se mostrou eficiente no processo de detenção temporária das águas e posterior infiltração. Isso foi possível devido à elevada taxa de infiltração na superfície do jardim de chuva piloto, com valor médio de 312 $\mathrm{mm} / \mathrm{h}$.Esse valor é característico de solos com classificação hidrológica do tipo A, estando em conformidade com a granulometria do substrato.
Em relação ao armazenamento, a camada de brita utilizada como estrutura para o armazenamento das águas pluviais infiltradas no sistema comportou-se de maneira adequada, garantindo a retenção temporária dos volumes infiltrados, como observado nos níveis piezométricos. Os níveis apresentaram correspondência positiva e rápida em relação à distribuição da precipitação ao longo do dia.

162 Melo, T. dos A. T. de; Coutinho, A. P.; Cabral, J. J. da S. P.; Antonino, A. C. D.; Cirilo, J. A. 
Diante da avaliação das funções de retenção, armazenamento e infiltração, pode-se constatar que o jardim de chuva piloto atingiu as perspectivas quanto ao amortecimento dos volumes produzidos pela área de drenagem adotada.

\section{Referências}

\section{ASSOCIAÇÃO BRASILEIRA DE NORMAS TÉCNICAS. NBR 7181: solo: análise granulométrica. Rio de Janeiro, 1984.}

ARAVENA, J. E.; DUSSAILLANT, A. StormWater Infiltration and Focused Recharge Modeling WithFinite-Volume Two-Dimensional Richards Equation: application to an experimental rain garden. Journal of Hydraulic Engineering, v. 135, n. 12, p. 1073-1080. 2009.

AZZOUT, Y.et al.Techniques Alternatives enAssainissementPluvial :choix, conception, realization et entretien.Paris: Lavoisier, 1994.

BAPTISTA, M.; NASCIMENTO, N.; BARRAUD, S. Técnicas Compensatórias em Drenagem Urbana. 2. ed. Porto Alegre: ABRH, 2011.

BRANDÃO, V. S. Infiltração da Água no Solo. 3. ed. Viçosa: UFV, 2006.

CLOTHIER, B. E.; VOGELER, I.; MAGESAN, G. N. The Breakdown of Water Repellency and Solute Transport Through a Hydrophobic Soil. Journal of Hydrology, v. 231-232, p. 255-264, 2000.

CHRISTENSEN, D.; SCHMIDT, A. R.An Approach to Analyze the Hydrologic Effects of Rain Gardens.In: INTERNATIONAL LOW IMPACT DEVELOPMENT CONFERENCE, Seattle, 2008.Proceedings...Seattle, 2008.

CUO, L. et al. Effects of a Century of Land Cover and Climate Change on the Hydrology of the Puget Sound Basin. Hydrological Processes, v. 23, n. 6, p. 907-933, 2009.

DAVIS, A. L. et al.BioretentionTechnology: overview of current practice and future needs. Journal of Environmental Engineering, v. 135, n. 3, p. 109-117, 2009.

DAVIS, A. P. Field Performance of Bioretention: hydrology impacts. Journal Hydrology Engineering, v. 13, n. 2, p. 90-95, 2008.

DAVIS, A. P. et al. Water Quality Improvement ThroughBioretentionMedia: nitrogen and phosphorus removal. Water Environment Research, v. 78, n. 3, p. 284-293, 2006.
DIETZ, M. E.; CLAUSEN, J. C. Saturation to Improve Pollutant Retention in a Rain Garden.Environmental Science \& Technology, v. 40, n. 4, p. 1335-1340, 2006.

DUNNETT, N.; CLAYDEN.A Rain Gardens: managing water sustainably in the garden and designed landscape. Portland: Workman, 2007.

DUSSAILlANT, A. R.; WU, C. H.; POTTER, K. W. Richards Equation Model of a Rain Garden. Journal of Hydrologic Engineering, v. 9, n. 3. p. 219-225, 2004.

EMPRESA DE MANUTENÇÃO E LIMPEZA URBANA. Tabela de Preços Para Contratação de Obras e Serviços de Engenharia. Prefeitura de Recife, 2011.

EMERSON, C. H.; TRAVER, R. G. Multiyear and Seasonal Variation of InfiltrationFromStormWater Best Management Practices. Journal of irrigation and Drainage Engineering, v. 134, n. 5, p. 598-605, 2008.

\section{ENVIRONMENTAL PROTECTION}

AGENCY.Preliminary Data Summary of Urban Storm Water Best Management Practices.

Washington, DC, 1999.EPA 821-R-99-012, EPA Office of water.

ERMILIO, J. R. Characterization Study of a Bio-Infiltration Stormwater BMP. 2005. Thesis - Department of Civil and Environmental Engineering, Villanova University, 2005.

FLYNN, K. M.; TRAVER, R. G. Green Infrastructure Life Cycle Assessment: a bioinfiltration case study. Ecological Engineering, v. 55, p. 9-22, 2013.

HE, Z.; DAVIS, A. P. Process Modeling of stormWater Flow in a BioretentionCell.Journal of Irrigation and Drainage Engineering, v. 137, n. 3, p. 121-131, 2011.

HORTON, R. E. An Approach Toward a Physical Interpretation of Infiltration Capacity. Soil Science Society of America Proceedings, v. 5, p. 399$417,1940$.

HSIEH, C.; DAVIS, A. P. Multiple-Event Study of BioretentionForTreatment of Urban Storm Water Runoff. In: DIFFUSE POLLUTION CONFERENCE, Dublin, 2003.Proceedings....Dublin, 2003.

HUNT, W. F. et al. Evaluating BioretentionHydrology and Nutrient Removal at Three Field Sites in North Carolina. Journal of Irrigation and Drainage Engineering, v. 132, n. 6, p. 600-608, 2006. 
INSTITUTO BRASILEIRO DE GEOGRAFIA E ESTATÍSTICA. Sinopse do Censo Demográfico 2010. Disponível em

<http://www.ibge.gov.br/home/>. Acessoem: 15 jan. 2011.

JENKINS, J. K. G.; WADZUK, B. M.; WELKER, A. L. Fines Accumulation and Distribution in a Storm-Water Rain Garden Nine Years Post Construction.Journal of irrigation and Drainage Engineering, v. 136, n. 12, p. 862-869, 2010.

LABORATÓRIO DE METEOROLOGIA DE PERNAMBUCO; INSTITUTO DE

TECNOLOGIA DE PERNAMBUCO.

Climatologia. Disponível em

〈http://www.itep.br/itep_lamepe/site/tela3.php〉. Acessoem: 13 dez. 2010.

LASSABATÈRE, L. et al.BeerkanEstimation of Soil Transfer Parameters ThroughInfiltration Experiments - BEST. Soil Science Society of American Journal, v. 70, n. 2, p. 521-532, 2006.

LE COUSTUMER, S. et al.The Influence of Design Parameters on Clogging of StormwaterBiofilters: a large-scale column study. Water Research, v. 46, n. 20, p. 6743-6752, 2012.

LI, J. Q.; ZHAO, W. W. Design and Hydrologic Estimation Method of Multi-Purpose Rain Garden: Beijing case study. In: INTERNATIONAL LOW IMPACT DEVELOPMENT CONFERENCE, Seattle, 2008.Proceedings...Seattle, 2008.

LI, J. Q.; CHE, W.; GE, R. L. Control Effects comparison of Three Kinds of Typical LID Infiltration and Emission Reduction Measures: Beijing case study. In: INTERNATIONAL LOW IMPACT DEVELOPMENT CONFERENCE, San Francisco, 2010. Proceedings...San Francisco, California, 2010.

MUTHANNA, T. M.; VIKLANDER, M.; THOROLFSSON, S. T. Seasonal Climatic Effects on the Hydrology of a Rain Garden.Hydrological Process, v. 22, n. 11, p. 1640-1649, 2008.

NASCIMENTO, N. O.; BAPTISTA, M. B. Técnicas Compensatórias em águas Pluviais. In: RIGHETTO, A. M. (Coord.). Manejo de Águas Pluviais Urbanas. Rio de Janeiro: Abes, 2009.

PHILIP, J. R. The Theory of Infiltration: 4. sorptivity and algebraic infiltration equations. Soil Science, v. 84, n. 3, p. 257-264, 1957.

\section{PRINCE GEORGE'S COUNTY. Bioretention} Manual.Department of Environmental Resources, Maryland.2007.
RAMOS, M. A.; AZEVEDO, J. R. G. Nova Equação de Chuvas Intensas Para a Cidade de Recife-Pernambuco. In:SIMPÓSIO DE RECURSOS HÍDRICOS DO NORDESTE, 10., Fortaleza,2010. Anais...Fortaleza, 2010.

ROY-POIRIER, A.; CHAMPAGNE, P.; FILION, Y. Review of BioretentionSystem Research and Design: past, present and future. Journal of Environmental Engineering, v. 136, n. 9, p. 878$889,2010$.

SANTOS, H. G. et al. Sistema Brasileiro de Classificação de Solos. Brasília: Serviço de Produção da Informação; Rio de Janeiro: Embrapa Solos, 2006.

SANTOS, P. T. S. et al.Telhado Verde: desempenho do sistema construtivo na redução do escoamento superficial. Ambiente Construído, Porto Alegre, v. 13, n. 1, p. 161-174, jan./mar. 2013.

SARTORI, A.; GENOVEZ, A. M. Critérios Para Classificação Hidrológica de Solos Tropicais Brasileiros. In:SIMPÓSIO BRASILEIRO DE RECURSOS HÍDRICOS, 19, Maceió, 2011.Anais... Maceió, 2011.

SARTORI, A.; GENOVEZ, A. M.; LOMBARDI NETO, F. Classificação Hidrológica de Solos Brasileiros Para a Estimativa da Chuva Excedente Com o Método do Serviço de Conservação do Solo dos Estados Unidos: parte 1, classificação. Revista Brasileira de Recursos Hídricos, v. 10, n. 4, p. 5-18, 2005 a.

SARTORI, A.; GENOVEZ, A. M.; LOMBARDI NETO, F. Classificação Hidrológica de solos Brasileiros Para a Estimativa da Chuva Excedente Com o Método do Serviço de Conservação do Solo dos Estados Unidos: parte 2. aplicação. Revista Brasileira de Recursos Hídricos, v. 10, n. 4, p. 19-29, 2005 b.

\section{SHARKEY, L. J. The Performance of} BioretentionAreas in North Carolina: a study of water quality, water quantity, and soil media. Raleigh, 2006.Thesis - North Carolina State University.Raleigh, 2006.

SILVA, F. C. da. (Coord.). Manual de Análises Químicas de Solos, Plantas e Fertilizantes. Campinas: Embrapa Informática Agropecuária; Rio de Janeiro: Embrapa Solos, 1999.

SOUZA, E. S. et al.Caracterização Hidrodinâmica de Solos: aplicação do método Beerkan. Revista Brasileira de Engenharia Agrícola e Ambiental, v. 12, n. 2, p. 128-135, 2008.

TROWSDALE, S. A.; SIMCOCK, R. Urban StormwaterTreatment Using Bioretention.Journal of Hydrology, v. 397, n. 3-4, p. 167-174, 2011. 
UNIVERSITY OF NEW HAMPSHIRE

STORMWATER CENTER. Data Report.

Durham, NH. 2009. CICEET.

WILLMOTT, C. J. et al. Statistics For the Evaluation and Comparison of Models. Journal of

Geophysical Research, v. 90, n. 5, p. 8995-9005, 1985.

WINSTON, R. J. et al. Certifying the LndscapeCommunity in Rain Garden Installation: the North Carolina experience. In:

INTERNATIONAL LOW IMPACT

DEVELOPMENT CONFERENCE, San

Francisco, 2010. Proceedings...San Francisco,

2010.

\section{Agradecimentos}

Os autores agradecem à Capes, pela concessão da bolsa de mestrado, e à Facepe, pela concessão das bolsas de doutorado, que possibilitaram o desenvolvimento desta pesquisa.

Tássia dos Anjos Tenório de Melo

Departamento de Engenharia Civil, Centro de Tecnologia | Universidade Federal de Pernambuco | Av. Acadêmico Hélio Ramos, s/n, Cidade Universitária | Recife - PE - Brasil | CEP 50741-530 | Caixa-Postal 780 | Tel.: (81) 2126-7751 | E-mail: melo.tassia@yahoo.com.br

Artur Paiva Coutinho

Departamento de Engenharia Civil, Centro de Tecnologia | Universidade Federal de Pernambuco | Avenida da Arquitetura, Cidade Universitária | Recife - PE - Brasil | CEP 50740-550 | Tel.: (81) 2126-7973 | E-mail: arthur.coutinho@hotmail.com

Jaime Joaquim da Silva Pereira Cabral

Departamento de Engenharia Civil, Centro de Tecnologia | Universidade Federal de Pernambuco | Av. Prof. Moraes Rego, 1235, Cidade Universitária | Recife - PE - Brasil | CEP 50670-901 | Tel.: (81) 2126-8223 Ramal 8223 | E-mail: jcabral@ufpe.br

\section{Antônio Celso Dantas Antonino}

Departamento de Energia Nuclear, Centro de Tecnologia | Universidade Federal de Pernambuco | Av. Prof. Luiz Freire, 1000, Cidade Universitária | Recife - PE - Brasil | CEP 50740-540 | Tel.: (81) 2126-7973 | E-mail: acda@ufpe.br

José Almir Cirilo

Departamento de Engenharia Civil, Centro de Tecnologia | Universidade Federal de Pernambuco | Av. Prof. Moraes Rego, 1235, Cidade Universitária | Recife - PE - Brasil | CEP 50740-530 | Tel.: (81) 3454-0482 | E-mail: almir.cirilo@gmail.com

\section{Revista Ambiente Construído}

Associação Nacional de Tecnologia do Ambiente Construído

Av. Osvaldo Aranha, $99-3^{\circ}$ andar, Centro

Porto Alegre - RS - Brasil

CEP $90035-190$

Telefone: +55 (51) 3308-4084

Fax: +55 (51) 3308-4054

www.seer.ufrgs.br/ambienteconstruido

E-mail: ambienteconstruido@ufrgs.br 